\title{
Regulation of Genome Stability by TEL1 and MEC1, Yeast Homologs of the Mammalian ATM and ATR Genes
}

\author{
Rolf J. Craven, ${ }^{* \dagger \dagger}$ Patricia W. Greenwell,* Margaret Dominska* and Thomas D. Petes ${ }^{*, 1}$ \\ *Department of Biology and Curriculum in Genetics and Molecular Biology and ${ }^{\dagger}$ Department of Surgery, University of North Carolina, \\ Chapel Hill, North Carolina 27599-3280
}

Manuscript received November 13, 2001

Accepted for publication February 19, 2002

\begin{abstract}
In eukaryotes, a family of related protein kinases (the ATM family) is involved in regulating cellular responses to DNA damage and telomere length. In the yeast Saccharomyces cerevisiae, two members of this family, TEL1 and MEC1, have functionally redundant roles in both DNA damage repair and telomere length regulation. Strains with mutations in both genes are very sensitive to DNA damaging agents, have very short telomeres, and undergo cellular senescence. We find that strains with the double mutant genotype also have $\sim 80$-fold increased rates of mitotic recombination and chromosome loss. In addition, the tel1 mec1 strains have high rates of telomeric fusions, resulting in translocations, dicentrics, and circular chromosomes. Similar chromosome rearrangements have been detected in mammalian cells with mutations in ATM (related to TEL1) and ATR (related to MEC1) and in mammalian cells that approach cell crisis.
\end{abstract}

$\mathrm{C}$ ANCER cells often have elevated rates of genome 1 instability of a variety of types including: (1) mutations and microsatellite alterations ( $\mathrm{MIN}^{-}$tumors), (2) chromosome nondisjunction ( $\mathrm{CIN}^{-}$tumors), and (3) translocations and other chromosome rearrangements (LeNGAuer et al. 1998). Mutations in human genes in a variety of DNA repair pathways, including mismatch repair, DNA repair checkpoints, recombinational repair, and nucleotide excision repair result in increased genome instability at the cellular level and increased predisposition to cancer (SCHAR 2001).

The telomeres of normal human cells shrink with each cell division (HARLEY 1995). When the telomeres reach a certain critical length, the cells arrest in a state called "senescence" (Hayflick and Moorhead 1961; Harley 1995). When treated with transforming agents, some types of mammalian cells escape senescence (resuming cell division), although most of these cells will subsequently die at a stage called "crisis." The transition to crisis is associated with elevated genome instability including the formation of dicentric and ring chromosomes (Counter et al. 1992). These aberrations are thought to be a consequence of the very short telomeres in the cells that have escaped the senescent state.

One important gene in the regulation of genome stability in mammalian cells is ATM, the gene mutated in patients with ataxia telangiectasia (SHILOH 1997). The cellular phenotypes in human cells lacking ATM include sensitivity to DNA damaging agents, elevated levels of mitotic recombination (MEYN 1993), and increased

\footnotetext{
${ }^{1}$ Corresponding author: Department of Biology, University of North Carolina, Chapel Hill, NC 27599-3280.

E-mail: tompetes@email.unc.edu

end-to-end chromosome fusions associated with shortened telomeres (PANDita et al. 1995). Patients with ATM are cancer prone (SHILOH 1997). Mutations in the structurally related gene ATR are associated with embryonic lethality and chromosomal fragmentation (BROwN and BALTIMORE 2000). ATM and ATR are proteins required for checkpoint responses to DNA damaging agents, such as the phosphorylation of a number of proteins that lead to cell cycle arrest in response to DNA damage (SHILOH 2001). It is likely that the elevated levels of genome instability observed in strains with ATM or ATR mutations reflect both inefficient repair of spontaneous DNA damage (such as double-stranded DNA breaks occurring during DNA replication) and defects in telomere replication.

The yeast Saccharomyces cerevisiae has genes related to ATM and ATR (CARr 1997; KeITH and SChreIBER 1999), TEL1 (GREENWELL et al. 1995; Morrow et al. 1995), and MEC1/ESR1 (Kato and Ogawa 1994; Weinert et al. 1994), respectively. Strains with single mutations in MEC1, but not TEL1, are sensitive to DNA damaging agents and fail to arrest the cell cycle in response to DNA damage or inhibition of DNA synthesis (WEINERT et al. 1994). Tellp appears to have a role in the repair of DNA damage that is functionally redundant with that of Mec1p because tel1 mec1 double mutant strains are more sensitive to DNA damaging agents than are mec1 strains (Morrow et al. 1995; SANchez et al. 1996; Usu I et al. 2001) and an extra copy of TEL1 partially suppresses the DNA damage sensitivity of $m e c 1$ strains (MoRRow et al. 1995). Strains with the tel1 mutation have greatly shortened telomeres, but do not undergo senescence (Lustig and Petes 1986). Although the effect of the mec1 mutation on telomere length is subtle, strains 
with the tell mecl double mutant genotype undergo cellular senescence with approximately the same kinetics as observed in strains that lack telomerase (RITcHIE et al. 1999).

Strains with mec1 mutations have multiple phenotypes in addition to their sensitivity to DNA damaging agents including: (1) defective regulation of nucleotide pools (ZHAO et al. 1998), (2) defective meiotic checkpoints and regulation of recombination (KATO and OGAWA 1994; Lydall et al. 1996; GRushcow et al. 1999), (3) loss of telomeric silencing (CRAven and Petes 2000), (4) inability to redistribute silencing proteins from the telomeres to the sites of double-strand DNA breaks (McAinsH et al. 1999; Mills et al. 1999), (5) deficiency in regulating the firing of DNA replication origins in response to reduced nucleotide pools (Santocanale and Diffley 1998), (6) reduced ability to prevent breakdown of DNA replication forks stalled as a consequence of DNA damage (Tercero and Diffley 2001), and (7) accumulated small single-stranded DNA synthesis intermediates (MERRILL and Holm 1999). At least some of the phenotypes associated with the mec1 mutation are likely to reflect the protein kinase activity associated with Mec1p, since a number of proteins involved in DNA replication and DNA repair, such as Rad53p (SANCHEz et al. 1996) and replication protein A (BRUSH et al. 1996), are phosphorylated in a Mec1p- and/or Tellp-dependent manner (Lowndes and Murguia 2000). The observation that some substrates undergo both Mec1p-dependent and Tellp-dependent phosphorylation is consistent with the finding that these proteins appear to have similar in vitro kinase activities (Mallory and Petes 2000; Paciotti et al. 2000).

The possible functional redundancy of Tellp and Mec1p in the repair of certain types of DNA damage is also argued by an analysis of gross chromosomal rearrangements (GCR; MyUnG et al. 2001b). GCR are detected as events that lead to the simultaneous loss of two closely linked genes (CHEN et al. 1998). Among the GCR events detected in tel1 mec1 strains were deletions associated with addition of telomeric repeats and translocations with nonhomologous chromosomes (MYUNG et al. 2001b). The rate of GCR in wild-type strains is very low, about $4 \times 10^{-10} /$ division. This rate is not elevated in tel1 strains, but is elevated $\sim 200$-fold in mec1 sml1 strains; strains with the tel1 mec1 sml1 genotype have an extremely high rate of GCR, $\sim 12,000$-fold higher than that of wild type (MyUnG et al. 2001b).

Below, we examine the effects of the tel1 and mec1 using several different assays for genome stability. We show that tel1 mec1 double mutant diploid strains have greatly elevated levels of chromosome loss and mitotic recombination. In addition, we demonstrate that tel1 mec1 haploid strains have a high rate of novel chromosome aberrations. Many of these aberrations involve the fusion of telomeric repeats, resulting in dicentric and circular chromosomes. We suggest that these aberrant chromosomes may be causally related to the elevated rates of chromosome instability and the senescence phenotype associated with the tel1 mec1 mutant.

\section{MATERIALS AND METHODS}

Strain constructions: All of the strains used in this study, except DFS188, were isogenic with W303a (a ade2-1 his3-11,15 ura3-1 leu2-3,112 trp1-1 rad5-535; Thomas and RothsteIN 1989; FAN et al. 1996) except for changes introduced by transformation or crosses with isogenic strains; all strains were $R A D 5$. The genotypes of these haploid strains are in Table 1. The genotype of the unrelated haploid DFS188 is a ura3-52 leu2-3, 112 lys2 his3 arg8::hisG (SIA et al. 2000). Diploids TPY100, TPY101, and MD150 were made by crossing DFS188 to RCY308-10d:CR19, RCY308-10d:CR2, and RCY308-10d:CR18, respectively.

Diploids to monitor mitotic recombination and chromosome loss were constructed by the following crosses: RCY317 (RCY308-3a × RCY308-3d), RCY318 (RCY308-2b × RCY308-7b), RCY319 (RCY308-1d × RCY308-4a), RCY320 (RCY308-11a × RCY308-10d), RCY328 (RCY324-21c × RCY324-4c), RCY332 (RCY329-9b × RCY329-5a), RCY333 (RCY327-3c × RCY327-9a), RCY339 (RCY337-6c × RCY337-12c), RCY340 (RCY337-3d × RCY337-4b), and RCY342 (RCY337-26a × RCY337-24b).

Mitotic recombination and chromosome loss assays: Mitotic recombination and chromosome loss were measured in diploids heterozygous for the recessive can 1 and hom 3 markers (Figure 1). For each rate estimate, we measured the frequencies of $\mathrm{Can}^{\mathrm{r}} \mathrm{Thr}^{+}$(mitotic recombination events) and $\mathrm{Can}^{\mathrm{r}}$ $\mathrm{Thr}^{-}$(chromosome loss events) cells in 15-20 independent cultures. From these frequency measurements, we calculated rates of mitotic recombination and chromosome loss using the method of the median (LeA and Coulson 1949). We calculated $95 \%$ confidence intervals on these rate estimates as described previously (WIERdL et al. 1996). Similar methods were used in haploid strains to obtain the forward mutation rates at the CAN1 locus (KoKoska et al. 2000).

Sequence analysis of can1 mutations: To determine the nature of the mutation in canavanine-resistant isolates, we examined 10-20 independent canavanine-resistant derivatives of each strain. We first performed PCR analysis using primers derived from the $5^{\prime}$ - and 3 '-ends of $C A N 1$ to determine whether the gene was present. If a DNA fragment of the expected size $(1.7 \mathrm{~kb})$ was present (class 1 mutation), the gene was sequenced at the UNC Automated Sequencing Facility. If no PCR product was produced (class 2 mutants), we did additional PCR reactions using primers derived from the region centromere distal to $C A N 1$ and from the 10-kb region between CAN1 and PCM1 (the essential gene closest to the telomere of $\mathrm{V}_{\mathrm{L}}$ ). None of the mutant derivatives retained any of the DNA sequences distal to CAN1; all had breakpoints between CAN1 and PCM1. The sequences of the primer pairs used for this analysis are available on request (rolf@email.unc.edu).

The fusion partners of these translocated chromosomes were identified using an "arbitrary" PCR strategy (CHEN et al. 1998; Myung et al. 2001a,b). Ten PCR reactions were performed with each derivative. Each reaction contained one primer derived from the $\mathrm{V}_{\mathrm{L}}$ breakpoint and one of the arbitrary primers designed by CHEN et al. (1998) and MYUng et al. (2001b). The specific primers that were used were: ARB1, ARB4, ARB5, ARB6, ARBG, ARBA, ARBT, ARBC, ARBT1, and ARBT2. Purified genomic DNA was amplified under lowstringency conditions (5 cycles of $95^{\circ}, 30 \mathrm{sec} ; 30^{\circ}, 30 \mathrm{sec}$; $68^{\circ}, 2.5 \mathrm{~min}$ ) followed by higher-stringency amplification (30 cycles of $\left.95^{\circ}, 30 \mathrm{sec} ; 55^{\circ}, 30 \mathrm{sec} ; 68^{\circ}, 2 \mathrm{~min}\right)$. After the first round of PCR, the products were then amplified again using 
a primer directed to the "tag" sequence (ARB2; CHEN et al. 1998) and a second $V_{L}$ primer located $100 \mathrm{bp}$ closer to the chromosomal breakpoint.

Two sets of control reactions were performed: amplification of genomic DNA from a strain harboring an intact $\mathrm{V}_{\mathrm{L}}$ chromosome and amplification of DNA from an isolate lacking the entire $\mathrm{V}_{\mathrm{L}}$ region telomere proximal to the $P C M 1$ gene. These controls reduced the number of false positives, reflecting PCR artifacts. DNA fragments that were specific to the class 2 canavanine-resistant mutant strains were excised from the gel, purified, and sequenced. Sequences were aligned using the BLAST sequence analysis program in the Stanford University Saccharomyces Genome Database (SGD).

Gel electrophoresis and Southern analysis: For standard Southern analysis, DNA was isolated (GUTHRIE and FINK 1991) from cells grown in liquid $(5 \mathrm{ml})$ YPD cultures at $30^{\circ}$. DNA was treated with various restriction enzymes and the resulting fragments were separated by electrophoresis using $0.8 \%$ agarose gel. Standard conditions of hybridization were used. Hybridization probes were prepared by PCR amplification of yeast genomic DNA. For analysis of the dicentric chromosome in RCY308-10d:CR19, we used PCR fragments derived from $\mathrm{V}_{\mathrm{L}}$ (P1, generated using primers 5'-GGATGATCTTGGAG ATCGC and 5'-GAGTCCAATTAGCTTCATCG) and $\mathrm{XV}_{\mathrm{L}}(\mathrm{P} 2$, generated using primers 5'-GGAATTTCGTTCCAACATCAA TACC and 5'-CTAGTTAAGCGAGCATGTC); P1 includes chromosome V sequences 3207-3500, and P2 has chromosome XV sequences 41416-42014 (numbering system of SGD). For analysis of the circular chromosome in RCY308-10d:CR18, we used a PCR fragment derived from $V_{R}$ (primers 5'-GAAAGTA TAATGGAGCAC and 5'-TACACAGACCATACATTAG); this fragment includes chromosome V sequences 569035-569500. A hybridization probe specific for the $\mathrm{Y}^{\prime}$ subtelomeric repeats was prepared as described by Craven and Petes (1999).

For analysis of intact chromosomes, we employed the methods described by GUTHRIE and FINK (1991). Both transverse alternating-field electrophoresis (TAFE; Beckman GeneLine) and contour-clamped homogeneous electric field (CHEF; BioRad CHEF Mapper) setups were used. Yeast chromosome size standards were purchased from New England Biolabs (Beverly, $\mathrm{MA})$. The chromosome $\mathrm{V}$-specific hybridization probe was P1 (described above). The chromosome VIII-specific probe containing ARG4 sequences was obtained by PCR amplification of genomic DNA with the primers $A R G 4-B c l$ I-F $\left(5^{\prime}-\right.$ TGAT CAAGTTGTTACCGATTTGAGA) and ARG4-BglII-R (5'-TTG TCCGAATCTCGAATCGATCTTTTG).

\section{RESULTS}

The purpose of these experiments was to monitor the effect of tell and mec1 mutations on the rates of several classes of genomic alterations including mitotic recombination, chromosome loss, and mutation. Mitotic recombination and chromosome loss rates were analyzed in diploid strains and mutation rates were determined in haploid strains. The genetic backgrounds of all strains were isogenic with W303a except for the mutational alterations described (Table 1). Since tel1 mec1 strains have very short telomeres and a senescent phenotype, as a control, we also examined the same classes of genomic alterations in $t l c 1$ strains that lack telomerase (SINGER and Gottschling 1994). Both $t l c 1$ and tel1 mec1 strains undergo cellular senescence (SINGER and GotTschLING 1994; RITCHIE et al. 1999), and produce postsenes- cent "survivors" by a recombination-dependent mechanism (Lundblad and BlackBuRn 1993; Ritchie et al. 1999). Type I survivors have amplified subtelomeric repeats, whereas type II survivors have amplified poly $\left(\mathrm{G}_{1-3} \mathrm{~T}\right)$ sequences (TENG and ZAKIAN 1999). In our experiments, both $t l c 1$ and tell mecl strains were type I postsenescent survivors.

Mitotic recombination and chromosome loss: We used a standard assay for measuring mitotic recombination and chromosome loss (HARTwell and SMith 1985). All diploids used in these experiments were heterozygous for mutations in CAN1 and HOM3, two markers located on opposite arms of chromosome V. Haploid strains with the can 1 mutation are sensitive to the drug canavanine and hom 3 strains require threonine. Since can 1 and hom 3 are recessive mutations, the diploid strains are sensitive to $\mathrm{Can}^{\mathrm{s}}$ and $\mathrm{Thr}^{+}$. Loss of the copy of chromosome $\mathrm{V}$ with the wild-type alleles for these markers (Figure 1a) results in a strain that is $\operatorname{Can}^{\mathrm{r}}$ and $\mathrm{Thr}^{-}$. In contrast, mitotic recombination (Figure 1b) results in strains that are $\mathrm{Can}^{\mathrm{r}}$, but $\mathrm{Thr}^{+}$.

Two further points concerning the mitotic recombination assay should be mentioned. First, the event diagrammed in Figure $1 \mathrm{~b}$ is a reciprocal mitotic crossover. Other types of mitotic recombination (gene conversion unassociated with crossingover or break-induced recombination) could produce a strain with the same phenotype (Paques and Haber 1999). Second, a Can ${ }^{\mathrm{r}} \mathrm{Thr}^{+}$ strain could also arise as a consequence of a mutation or deletion of the wild-type CAN1 gene. Since mutation and deletion rates are several orders of magnitude less than the observed mitotic recombination rates, the contribution of these mechanisms is negligible.

The rates of chromosome loss and mitotic recombination (Table 2) were determined as described in MATERIALS AND METHODS. We examined the effects of two different mec1 mutations: mec1-21, a haploid-viable allele (SANCHEZ et al. 1996) with a point mutation located outside of the kinase domain (Craven and Petes 2000; Mallory and Petes 2000), and mec1- $\Delta$, a complete deletion of MEC1 that is inviable without an accompanying sml1 mutation (ZHAO et al. 1998). The null mutation had a stronger effect on both mitotic recombination and chromosome loss rates, elevating both rates $\sim 10$-fold. Similar effects have been observed in independent experiments by KLEIN (2001). Strains with either tel1 or sml1 single mutations had approximately wild-type rates of chromosome loss and mitotic exchange, although tel1 mutants have slightly (3-fold) elevated rates of mitotic recombination and chromosome loss in other genetic backgrounds (GREenwell et al. 1995). Strains with the tel1 mec1-21 or tel1 mec1- $\Delta$ sml1 genotypes had 80- to 90 -fold elevations in the rates of both mitotic recombination and chromosome loss. These rates are greater than expected for additive or multiplicative effects of the single mutations.

As described above, tel1 mec1 strains continuously 
TABLE 1

Haploid strains derived from W303a

\begin{tabular}{|c|c|c|}
\hline Strain name & Relevant genotype $^{a}$ & Construction or reference \\
\hline Y602 & $\begin{array}{l}\text { mec1- } \Delta:: H I S 3+\text { pBAD45 (MEC1 gene on CEN-URA3- } \\
\text { containing plasmid) }\end{array}$ & DESANY et al. (1998) \\
\hline MC42-2d & CAN1 RAD5 & MC42 $($ W303a $\times$ HLK1042-1C) spore \\
\hline JMY314-1a & sml1- $\Delta:: H I S 3$ RAD5 & JMY314 spore (Mallory and Petes 2000) \\
\hline KRY97 & $\alpha$ xrs $2:: k a n M X$ & Ritchie and Petes (2000) \\
\hline RCY278-1b & tel1- $\Delta:: k a n M X$ mec1-21 RAD5 TELXV $V_{L}:: U R A 3$ & RCY278 spore (Craven and Petes 2001) \\
\hline RCY306-6b & mecl-21 CAN1 hom3-10 RAD5 & RCY306 (RCY269-12b × HLK1042-1C) spore \\
\hline RCY307-4a & 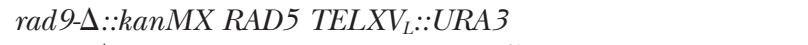 & Craven and Petes (2001) \\
\hline RCY308-1c & $\alpha$ tel1- $\Delta::$ kanMX CAN1 hom3-10 RAD5 & RCY308 (RCY278-1b × HLK1042-1C) spore \\
\hline RCY308-1d & $\alpha$ tel1- $\Delta:: k a n M X$ CAN1 RAD5 & RCY308 $($ RCY278-1b × HLK1042-1C) spore \\
\hline RCY308-2b & mec1-21 hom3-10 RAD5 TELXV $V_{L}: U R A 3$ & RCY308 (RCY278-1b × HLK1042-1C) spore \\
\hline RCY308-10d & a tel1- $\Delta:: k a n M X$ mec1-21 CAN1 RAD5 & RCY308 (RCY278-1b × HLK1042-1C) spore \\
\hline RCY308-11a & tel1- $::$ kanMX mec1-21 hom3-10 RAD5 TELXV $V_{L}: \because U R A 3$ & RCY308 (RCY278-1b × HLK1042-1C) spore \\
\hline RCY324-4c & $\alpha$ tlc1- $\Delta:: L E U 2$ CAN1 RAD5 & RCY324 (KRY229-9a × HLK1042-1C) spore \\
\hline RCY324-21c & tlc1- $\Delta:: L E U 2$ hom3-10 RAD5 & RCY324 (KRY229-9a × HLK1042-1C) spore \\
\hline RCY325-25a & a xrs2::kanMX CAN1 hom3-10 RAD5 & RCY325 (RCY306-6b × KRY97) spore \\
\hline RCY327-3c & $\operatorname{rad} 9 \Delta:: k a n M X$ hom3-10 RAD5 & RCY327 (RCY307-4a × RCY325-25a) spore \\
\hline RCY327-9a & $\alpha \operatorname{rad} 9 \Delta:: k a n M X$ CAN1 RAD5 & RCY327 (RCY307-4a × RCY325-25a) spore \\
\hline RCY329-5a & $\alpha$ tel1- $::$ kanMX rad9D::kanMX hom3-10 RAD5 & RCY329 (RCY307-4a × RCY308-1c) spore \\
\hline RCY329-9b & tel1- $\Delta:: k a n M X$ rad9D::kanMX CAN1 RAD5 & RCY329 (RCY307-4a × RCY308-1c) spore \\
\hline RCY335-2c & mec1- $\Delta:: H I S 3$ sml1- $\Delta:: H I S 3$ RAD5 & RCY335 (Y602 × JMY314-1a) spore \\
\hline RCY337-3d & tel1- $\Delta:: k a n M X$ mec1- $\Delta:: H I S 3$ sml1- $\Delta:: H I S 3$ CAN1 RAD5 & RCY337 (RCY335-2c × RCY308-1c) spore \\
\hline
\end{tabular}

${ }^{a}$ All strains are isogenic with W303a (Thomas and Rothstein 1989) except for changes introduced by transformation. Only differences from the progenitor genotype of W303a (a leu2-3,112 his3-11 ura3-1 ade2-1 trp1-1 can1-100 rad5-535) are shown in the "Relevant genotype" column.

shorten their telomeres and undergo cellular senescence (Ritchie et al. 1999). To determine whether this phenotype was relevant to the genomic instability observed in tel1 mec1 cells, we also examined the rates of mitotic recombination and chromosome loss in strains lacking telomerase ( $t l c 1$ strains). The $t l c 1$ mutation had only modest (threefold) effects, indicating that the elevated rates of genome instability in the tel1 mecl cells are not solely attributable to a deficiency in telomere length regulation.

Since the mecl mutation results in a DNA damage checkpoint deficiency, we also determined whether a mutation in a different checkpoint gene, RAD9 (WEINERT 1998), would have similar effects. Mutant rad9 strains had slightly elevated mitotic recombination rates and substantially elevated chromosome loss rates (Table 2), as reported previously (WEINERT and HARTWELL 1990). In contrast to the tel1 mec1 strain, however, the tel1 rad9 strain had nearly wild-type rates of chromosome loss and mitotic exchange. In addition, the tel1 mutation suppresses the elevated rate of chromosome loss observed in the rad9strain. Although the interpretation of this observation is not clear, it is possible that the $\operatorname{rad} 9$ mutation results in DNA lesions that are transduced by competing Mec1p-and Tellp-dependent pathways. If Meclp transduces the signal more efficiently than Tellp, then loss of Tellp might result in a more efficient checkpoint response and a decreased rate of chromosome loss.

Mutator phenotype: We also examined mutation rates in haploid tel1 mec1 strains and several other relevant genotypes using the standard CAN1 forward mutation assay that we have employed in previous studies (Kokoska et al. 2000). Mutations that inactivate Can1p, an arginine permease, result in strains that are resistant to canavanine. The mutation rate data are shown in Table 3. All 

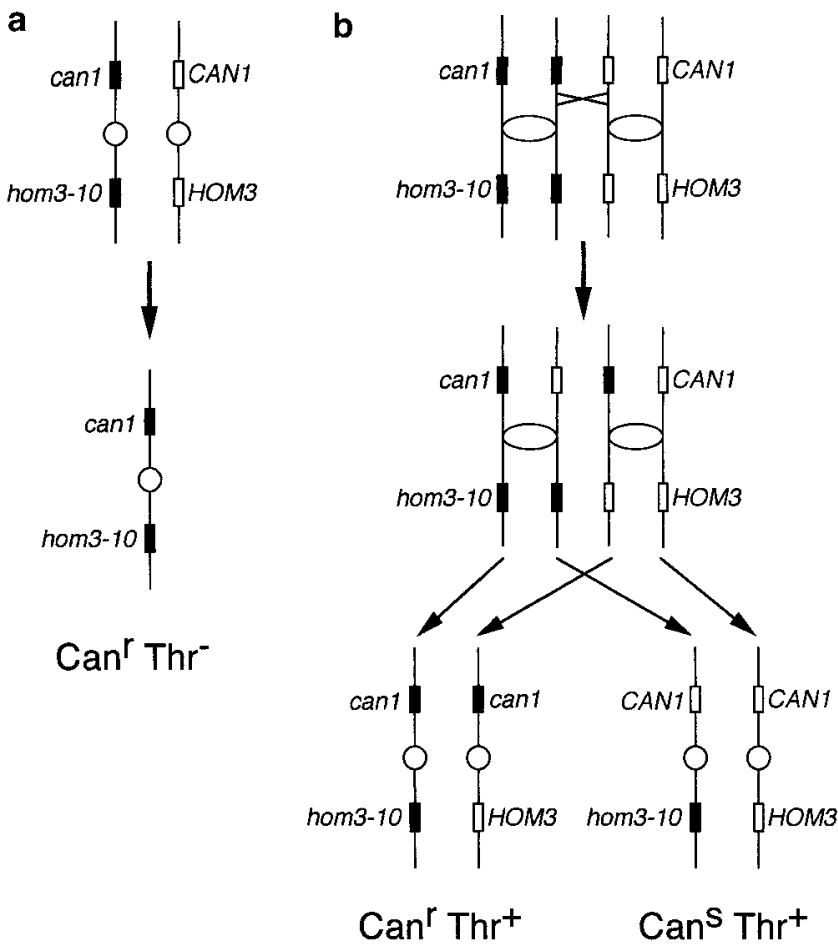

FIgURE 1.-Assay for chromosome loss and mitotic recombination in diploid yeast strains. Diploids heterozygous for the recessive mutations can 1 and hom 3 are sensitive to the drug canavanine and do not require threonine. (a) Loss of the chromosome containing the wild-type alleles for these markers results in derivatives that are $\mathrm{Can}^{\mathrm{r}}$ and $\mathrm{Thr}^{-}$. (b) A mitotic crossover between the CAN1 locus and the centromere, coupled with segregation of the homologs with the can 1 mutation, will generate derivatives that are $\mathrm{Can}^{\mathrm{r}}$, but $\mathrm{Thr}^{+}$. Other types of mitotic recombination events (gene conversion or breakinduced recombination) can yield the same product.

rates are averages of rates from two experiments, involving at least 15 independent cultures/experiment.

Single mec1, tell, or sml1 mutations had no significant mutator phenotype. In contrast, strains of the tel1 mec1-21 or tel1 mec1- $\Delta$ sml1- $\Delta$ genotypes had strong (50to 200-fold) mutator effects. Strains with the $t l c 1$ mutation had a substantial (8-fold) mutator phenotype, but the effects of $t l c 1$ were much more modest than those observed for the tel1 mecl strains. The rad9 mutation had no mutator phenotype as a single mutation or in combination with tell.

We also analyzed sequence alterations at the CAN1 locus in a number of independent canavanine-resistant derivatives in the wild-type and mutant strains (Table 4). By PCR analysis (described in MATERIALS AND METHoDs), we first determined whether the CAN1 locus was deleted. Class 1 mutants retained the locus, and subsequent sequence analysis indicated that these mutants had a point mutation or frameshift within CAN1. Class 1 alterations were the primary type of change observed in wild-type, mec1, tell, and tlc1 strains. Class 2 mutants were strains with deletions of all or part of the CAN1 gene and loss of all DNA sequences distal to CAN1 on chromosome V. As discussed below, many of the class 2 alterations were fusions of the deleted copy of chromosome $\mathrm{V}$ to DNA sequences derived from a different homolog. Class 2 mutations represented most of the canavanine-resistant derivatives in the tell mecl strains (Table 4).

We analyzed the class 2 mutations using the methods developed by Chen et al. (1998). The CAN1 locus is located on the left arm of chromosome $\mathrm{V} \sim 32 \mathrm{~kb}$ from the telomere. Since no essential genes are distal to CAN1, deletions or chromosomal rearrangments that delete all of the sequences from CAN1 to the end of the chromosome are haploid viable. The first essential gene centromere proximal to CAN1 is PCM1 (located $\sim 44 \mathrm{~kb}$ from the telomere). Consequently, to determine the region of chromosome $\mathrm{V}$ that was retained in the class 2 mutations, we performed PCR using pairs of primers located centromere distal to $C A N 1$ and at $\sim 1-\mathrm{kb}$ intervals between PCM1 and CAN1. All class 2 mutant strains lacked all of the DNA sequences centromere distal to CAN1 and had a breakpoint somewhere between CAN1 and PCM1.

To identify the non-chromosome $\mathrm{V}$ sequences at the fusion breakpoint, we then performed 10 additional PCR reactions (details in MATERIALS AND METHODS). All reactions contained one primer in common, a primer with the most centromere-distal chromosome $\mathrm{V}$ sequences. The second primer (a pool of degenerate primers; Chen et al. 1998; Myung et al. 2001b) was unique to each reaction. For example, one such primer (ARB1; CHEN et al. 1998) had the sequence: 5'-GGCCA CGCGTCGACTAGTACNNNNNNNNNNGATAT, with $\mathrm{N}$ representing an equal mixture of the four bases; the 20 base pairs at the $5^{\prime}$-end of the primer act as a tag for a second round of PCR. Following the first round of PCR with the 10 reactions, a second round of nested PCR was performed. DNA fragments that were unique to the class 2 mutants were sequenced.

The DNA sequences for 13 class 2 mutants are shown in Figure 2. In all of these strains, we observed DNA sequences derived from chromosome $\mathrm{V}_{\mathrm{L}}$ (breakpoints varying between 32444 and 42860) fused to DNA sequences derived from a different chromosome or the opposite end of the same chromosome. As observed in other studies (Chen et al. 1998; Mrung et al. 2001a,b), some of these fusions involved a small amount of DNA sequence homology at the fusion junction (indicated by underlining in Figure 2), whereas other fusions involved no detectable homology; the lack of substantial sequence homology at the breakpoints indicates that the fusions involve nonhomologous end-joining (NHEJ) pathways rather than homologous recombination (Paques and Haber 1999). In 12 of the 13 class 2 mutants, the fusions involved chromosomal sequences. In one mutant (RCY337-3d:CR7), DNA sequences derived 
TABLE 2

Mitotic recombination and chromosome loss rates in diploid strains

\begin{tabular}{|c|c|c|c|c|}
\hline Genotype (strain name) ${ }^{a}$ & $\begin{array}{l}\text { Mitotic recomb. } \\
\text { rates }(95 \% \text { CL })^{b}\end{array}$ & $\begin{array}{l}\text { Normalized } \\
\text { mit. recomb. } \\
\text { rates }^{c}\end{array}$ & $\begin{array}{l}\text { Chrom. loss rates } \\
\qquad(95 \% \mathrm{CL})^{b}\end{array}$ & $\begin{array}{c}\text { Normalized } \\
\text { chrom. loss } \\
\text { rates }^{c}\end{array}$ \\
\hline Wild type (RCY317) & $\begin{array}{l}2.7 \times 10^{-5}(2.4-3.1) \\
2.8 \times 10^{-5}(2.7-3.3)\end{array}$ & 1 & $\begin{array}{l}2.5 \times 10^{-6}(1.1-3.4) \\
2.8 \times 10^{-6}(1.8-4.3)\end{array}$ & 1 \\
\hline mec1-21 (RCY318) & $\begin{array}{l}5.0 \times 10^{-5}(4.7-6.8) \\
6.3 \times 10^{-5}(5.7-7.8)\end{array}$ & 2 & $\begin{array}{l}1.8 \times 10^{-5}(1.3-2.1) \\
2.3 \times 10^{-5}(1.8-3.0)\end{array}$ & 8 \\
\hline$m e c 1-\Delta$ sml1- $\Delta$ (RCY339) & $\begin{array}{l}2.7 \times 10^{-4}(2.4-3.0) \\
2.7 \times 10^{-4}(2.2-3.2)\end{array}$ & 10 & $\begin{array}{l}4.3 \times 10^{-5}(2.7-5.1) \\
2.9 \times 10^{-5}(2-4.6)\end{array}$ & 13 \\
\hline sml1- $\Delta$ (RCY342) & $\begin{array}{l}3.1 \times 10^{-5}(2.7-4.4) \\
4.9 \times 10^{-5}(4.4-5.2)\end{array}$ & 1.4 & $\begin{array}{l}5.5 \times 10^{-6}(4.7-6.7) \\
3.6 \times 10^{-6}(1.9-5.1)\end{array}$ & 1.7 \\
\hline tel1- $\Delta$ (RCY319) & $\begin{array}{l}3.4 \times 10^{-5}(2.9-3.7) \\
3.2 \times 10^{-5}(2.5-3.6)\end{array}$ & 1.2 & $\begin{array}{l}7.6 \times 10^{-6}(6.3-8.3) \\
4.8 \times 10^{-6}(3.4-6.3)\end{array}$ & 2.3 \\
\hline tel1- $\Delta$ mec1-21 (RCY320) & $\begin{array}{l}2.2 \times 10^{-3}(1.2-2.9) \\
2.1 \times 10^{-3}(1.4-3.5)\end{array}$ & 79 & $\begin{array}{l}2.7 \times 10^{-4}(1.5-5.6) \\
1.6 \times 10^{-4}(0.5-3.2)\end{array}$ & 81 \\
\hline tel1- $\Delta$ mec1- $\Delta$ sml1- (RCY340) & $\begin{array}{l}2.6 \times 10^{-3}(1.9-4.7) \\
2.2 \times 10^{-3}(1.7-4.1)\end{array}$ & 86 & $\begin{array}{l}2.0 \times 10^{-4}(1.6-3.2) \\
2.7 \times 10^{-4}(1.6-3.2)\end{array}$ & 89 \\
\hline$t l c 1-\Delta$ (RCY328) & $\begin{array}{l}1.0 \times 10^{-4}(0.8-1.8) \\
8.9 \times 10^{-5}(6.2-24)\end{array}$ & 3.4 & $\begin{array}{l}1.0 \times 10^{-5}(0.3-2.4) \\
6.5 \times 10^{-6}(3.5-9.3)\end{array}$ & 3.1 \\
\hline rad9 (RCY333) & $\begin{array}{l}6.7 \times 10^{-5}(6.3-7.2) \\
5.6 \times 10^{-5}(4.8-6.3)\end{array}$ & 2.2 & $\begin{array}{l}3.3 \times 10^{-5}(2.2-3.7) \\
3.4 \times 10^{-5}(2.8-3.9)\end{array}$ & 13 \\
\hline tel1- $\Delta$ rad9 (RCY332) & $\begin{array}{l}2.3 \times 10^{-5}(1.5-2.5) \\
2.6 \times 10^{-5}(2.3-2.8)\end{array}$ & 0.9 & $\begin{array}{l}1.1 \times 10^{-5}(0.7-1.4) \\
8.3 \times 10^{-6}(5.8-8.7)\end{array}$ & 3.6 \\
\hline
\end{tabular}

\footnotetext{
${ }^{a}$ All strains are homozygous for the indicated mutation and heterozygous for the can 1 and hom 3-10 alleles as indicated in Figure 1.

${ }^{b}$ For each genotype, two independent rate measurements were done. For each rate measurement, we measured the frequencies of $\mathrm{Can}^{\mathrm{r}} \mathrm{Thr}^{-}$cells (representing chromosome loss events) and the frequencies of $\mathrm{Can}^{\mathrm{r}} \mathrm{Thr}^{+}$cells (representing mitotic recombination events) in at least 15 independent cultures. These frequencies were converted to rates using the method of the median (LEA and Coulson 1949). We calculated 95\% confidence limits as described previously (WIERd et al. 1996). Although we assume that the $\mathrm{Can}^{\mathrm{r}} \mathrm{Thr}^{-}$ cells reflect chromosome loss events (HARTwELL and SMith 1985), we cannot rule out the possibility that a fraction of these cells result from concerted double crossover events.

${ }^{c}$ The average rate for each mutant strain was divided by the average rate found in the wild-type strain.
}

from the $2 \mu$ plasmid were fused to chromosome $\mathrm{V}$ sequences; a similar fusion was also observed by CHEN and Kolodner (1999). In 5 of the 12 class 2 mutants involving chromosomal sequences, the breakpoints were in the telomeric repeats $\left[\operatorname{poly}\left(\mathrm{G}_{1-3} \mathrm{~T}\right) / \operatorname{poly}\left(\mathrm{C}_{1-3} \mathrm{~A}\right)\right]$ or in the subtelomeric $\mathrm{X}$ and $\mathrm{Y}^{\prime}$ repeats.

Another variable was the relative orientation of the fusions. Every single-stranded yeast DNA sequence (written $5^{\prime}$ to $3^{\prime}$ ) can be oriented toward the centromere or toward the telomere by using information in the Stanford Genome Database. On the basis of the orientation of the DNA sequences at the breakpoints, six of the fusions had sequences that were oriented in the same direction on each side of the breakpoint and, thus, would be expected to reflect the formation of two monocentric chromosomes. Six fusions had sequences oriented in opposite directions on each side of the breakpoint and would be expected to reflect the forma- tion of a dicentric chromosome plus an acentric fragment or a circular chromosome (as discussed below).

Types of chromosome rearrangments that could lead to class 2 mutations are shown in Figure 3, a-d. In some cases, the chromosomes expected in the canavanineresistant derivative depend on the location of the breakpoint. For example, in Figure 3b, if the breakpoint results in loss of essential DNA sequences from the dicentric chromosome, the nontranslocated derivative must segregate with the dicentric to recover a viable canavanine-resistant derivative. Alternatively, if the recombination/fusion involves telomeric sequences (Figure 3c), strains that have only the dicentric chromosome would be viable. It should be pointed out that two mechanisms could generate canavanine-resistant strains with a fusion between telomeric sequences and chromosome $\mathrm{V}_{\mathrm{L}}$ : fusion with the telomere of a nonhomologous chromosome (Figure 3c) or an intrachromosomal fusion 
TABLE 3

Forward mutation rates at the CAN1 locus in haploid strains

\begin{tabular}{|c|c|c|c|}
\hline Genotype (strain name) ${ }^{a}$ & $\begin{array}{c}\text { Mutation rates } \\
\text { in duplicate experiments } \\
(95 \% \text { confidence limits })^{b}\end{array}$ & Av. rate & $\begin{array}{l}\text { Rate } \\
\text { normalized to } \\
\text { wild-type rate }\end{array}$ \\
\hline Wild type (RCY308-3a) & $\begin{array}{l}2.4 \times 10^{-7}(1.8-3.6) \\
2.3 \times 10^{-7}(2.1-2.6)\end{array}$ & $2.4 \times 10^{-7}$ & 1 \\
\hline mec1-21 (RCY308-7b) & $\begin{array}{l}3.0 \times 10^{-7}(2.5-3.8) \\
3.2 \times 10^{-7}(2.9-3.9)\end{array}$ & $3.1 \times 10^{-7}$ & 1.3 \\
\hline mec1- $\Delta$ sml1- $($ RCY337-6c) & $\begin{array}{l}4.7 \times 10^{-7}(4.2-5.0) \\
5.1 \times 10^{-7}(4.4-5.8)\end{array}$ & $4.9 \times 10^{-7}$ & 2.0 \\
\hline sml1- $\Delta$ (RCY337-26a) & $\begin{array}{l}2.4 \times 10^{-7}(1.8-2.9) \\
3.3 \times 10^{-7}(2.7-3.7)\end{array}$ & $2.9 \times 10^{-7}$ & 1.2 \\
\hline tel1- $\Delta$ (RCY308-1d) & $\begin{array}{l}3.1 \times 10^{-7}(2.7-3.5) \\
3.7 \times 10^{-7}(3.0-4.8)\end{array}$ & $3.4 \times 10^{-7}$ & 1.4 \\
\hline tel1- $\Delta$ mec1-21 (RCY308-10d) & $\begin{array}{l}1.1 \times 10^{-5}(0.9-1.6) \\
1.6 \times 10^{-5}(1.2-1.9)\end{array}$ & $1.4 \times 10^{-5}$ & 58 \\
\hline tel1- $\Delta$ mec1- $\Delta$ sml1- $($ RCY337-3d) & $\begin{array}{l}5.0 \times 10^{-5}(3.5-6.9) \\
5.5 \times 10^{-5}(1.4-7.2)\end{array}$ & $5.3 \times 10^{-5}$ & 221 \\
\hline tlc1- $\Delta$ (RCY324-4c) & $\begin{array}{l}1.2 \times 10^{-6}(0.7-3.1) \\
2.7 \times 10^{-6}(1.7-4.5)\end{array}$ & $2.0 \times 10^{-6}$ & 8 \\
\hline rad9 (RCY327-9a) & $\begin{array}{l}1.4 \times 10^{-7}(1.2-1.7) \\
1.7 \times 10^{-7}(2.7-3.4)\end{array}$ & $1.6 \times 10^{-7}$ & 0.7 \\
\hline tel1- $\Delta$ rad9 (RCY329-9b) & $\begin{array}{l}3.2 \times 10^{-7}(2.5-3.5) \\
3.0 \times 10^{-7}(2.7-3.4)\end{array}$ & $3.1 \times 10^{-7}$ & 1.3 \\
\hline
\end{tabular}

${ }^{a}$ All strains are CAN1 derivatives of W303a (Thomas and RothsteIN 1989); complete genotypes are given in Table 1.

${ }^{b}$ For each experiment, the frequency of canavanine-resistant mutant cells in at least 15 independent cultures was measured. These frequencies were converted to rates using the method of the median (LEA and CouLson 1949). We calculated 95\% confidence limits as described previously (WIERDL et al. 1996).

resulting in formation of a circular molecule (Figure $3 d$ ). Although (as described below) we demonstrated one example of both types of telomeric fusions, we have not distinguished these two possibilities for most of the telomeric fusions. Circularization of chromosomes has been observed in Schizosaccharomyces pombe strains with mutations in homologs of TEL1 and MEC1 (NAITO et al. 1998).

Physical and genetic analysis of a class 2 strain with a fusion between chromosome $V_{L}$ and $\mathrm{XV}_{\mathrm{L}}$ sequences (RCY308-10d:CR19) and a class 1 control strain (RCY30810d:CR2): Since PCR amplification with degenerate primers might produce DNA fragments artifactually, we did several experiments to confirm our conclusions with one class 1 (RCY308-10d:CR2) and one class 2 (RCY30810d:CR19) mutant. The orientation of the fusion sequences in RCY308-10d:CR19 (Figure 2b) would be expected to produce a dicentric chromosome with all of the essential DNA sequences of both chromosome $\mathrm{V}$ and XV translocation. We confirmed the structure of the fusion junction by Southern analysis (Figure 4). The junction had the restriction fragments expected from our sequence of the fusion junction and the restriction maps derived from the untranslocated chromosomes. In contrast, RCY308-10d:CR2 had the DNA fragments predicted from unrearranged copies of chromosomes $\mathrm{V}$ and XV (data not shown).

We also showed genetic linkage between chromosome $\mathrm{V}$ and XV markers in a diploid (TPY100) formed by mating RCY308-10d:CR19 (can1 ARG8) with DFS188 (CAN1 arg8). Since the ARG8 gene is located $\sim 60 \mathrm{~kb}$ from the left telomere of chromosome XV, both heterozygous markers are near the putative fusion breakpoint. For strains heterozygous for two unlinked markers, in which at least one marker is also unlinked to the centromere, the expected ratio of parental ditype (PD) to nonparental ditype (NPD) to tetratype (T) tetrads is 1:1:4; linkage is indicated by a significant excess of PD tetrads over NPD tetrads. Of 18 tetrads with four viable spores derived from TPY100, 17 were PD tetrads and 1 was tetratype, indicating tight genetic linkage of markers on nonhomologous chromosomes. As a control, we mated a class 1 mutant (RCY308-10d:CR2) with DFS188. In this diploid strain (TPY101), we observed 6 PD, 3 
TABLE 4

Types of mutations in canavanine-resistant isolates ${ }^{a}$

\begin{tabular}{|c|c|c|c|}
\hline Genotype $^{b}$ & $\begin{array}{c}\text { No. of } \\
\text { mutants analyzed }^{c}\end{array}$ & $\begin{array}{c}\text { No. of class } 1 \\
\text { mutants (no. sequenced })^{d}\end{array}$ & $\begin{array}{c}\text { No. of class } 2 \\
\text { mutants (no. sequenced) }\end{array}$ \\
\hline Wild type & 20 & $20(20)$ & $0(0)$ \\
\hline mec1-21 & 13 & $9(8)$ & $4(0)$ \\
\hline mec1- $\Delta$ sml1- $\Delta$ & 20 & $16(10)$ & $4(0)$ \\
\hline tell- $\Delta$ & 20 & $17(7)$ & $3(0)$ \\
\hline tel1- $\Delta$ mec1-21 & 20 & $3(3)$ & $17(7)$ \\
\hline tel1- $\Delta$ mec1- $\Delta$ sml1- $\Delta$ & 20 & $1(1)$ & $19(6)$ \\
\hline$t l c 1-\Delta$ & 35 & $34(34)$ & $1(0)$ \\
\hline
\end{tabular}

${ }^{a}$ The sequences of the mutations and chromosome alterations in independent canavanine-resistant isolates were determined as described in the text. The positions of the class 1 mutations and their specific sequences are given on the Website: http://www.unc.edu/ rolf/Home.txt.

${ }^{b}$ All strains are CAN1 derivatives of W303a (Thomas and Rothstein 1989); complete genotypes are given in Table 1. The strain names used for each genotype are described in the text.

${ }^{c}$ This column represents the number of independent canavanine-resistant derivatives examined for the presence of the CAN1 gene by PCR.

${ }^{d}$ This column represents the number of canavanine-resistant derivatives that retained the CAN1 gene (class 1 mutants) and the number of these derivatives that were sequenced (in parentheses).

${ }^{e}$ This column represents the number of canavanine-resistant derivatives that lost the CAN1 gene (class 2 mutants) and the number of these derivatives that were sequenced (in parentheses). The sequences of the breakpoints of class 2 mutants are shown in Figure 2.

$\mathrm{NPD}$, and $10 \mathrm{~T}$ tetrads. The segregation pattern in TPY101 indicates that the linkage between CAN1 and ARG8 in RCY308-10d:CR19 is not a property of the progenitor RCY308-10d strain. In summary, these results confirm the existence of a fusion between chromosome V and XV sequences in RCY308-10d:CR19.

Another observation suggestive of a chromosome aberration in RCY308-10d:CR19 was the pattern of spore viability in TPY100. Of the tetrads dissected, the percentages of tetrads with $4,3,2,1$, and 0 viable spores were $7,39,32,13$, and 8 , respectively; the total spore viability was $56 \%$. In contrast, in the diploid TPY101, the percentages of tetrads with $4,3,2,1$, and 0 viable spores were $59,19,11,6$, and 5 (total spore viability of $81 \%$ ). Poor spore viability is expected in strains containing dicentric chromosomes because the independent attachment of microtubules to two centromeres can lead to loss or fracture of the dicentric chromosome (HABER et al. 1984). Since similar patterns of spore inviability are also observed in strains heterozygous for translocations (Mikus and Petes 1982), however, these data are suggestive rather than conclusive.

We also examined the sizes of the chromosomes in strains RCY308-10d:CR2 and RCY308-10d:CR19 by gel electrophoresis. The RCY308-10d:CR2 strain, as well as its TEL1 MEC1 derivative, has a chromosome $\mathrm{V}$ that is slightly shorter than the "standard" chromosome $\mathrm{V}$ (Figure 5a). If the $\mathrm{V}_{\mathrm{L}}-\mathrm{XV}_{\mathrm{L}}$ chromosome fusion in RCY308-10d:CR19 involved all of the DNA sequences of chromosome XV (with loss of only the terminal $500 \mathrm{bp}$ ) and most of the DNA sequences of chromosome $\mathrm{V}$ (40705-576869), the dicentric would be $\sim 1600 \mathrm{~kb}$. Using a probe for $\mathrm{V}_{\mathrm{L}}$ sequences near the junction (P1,
Figure $4 \mathrm{a}$ ), by OFAGE analysis, we found that the $\mathrm{V}_{\mathrm{L}}-\mathrm{XV}_{\mathrm{L}}$ fusion chromosome in RCY308-10d:CR19 was $\sim 840 \mathrm{~kb}$ (lane 2, Figure $5 \mathrm{~b}$ ). On the basis of these data, we suggest that, following the initial formation of the dicentric chromosome, there was a secondary chromosome rearrangment, yielding a V-XV translocation that lost some of the DNA sequences derived from XV.

Several additional points should be made concerning the chromosome aberrations of RCY308-10d:CR19. First, we do not know the exact nature of the V-XV translocation. It is not clear whether the $840-\mathrm{kb} \mathrm{V}-\mathrm{XV}$ chromosome in RCY308-10d:CR19 is dicentric or became monocentric as a consequence of the secondary rearrangement; secondary rearrangements resulting in loss of one centromere from a dicentric have been described previously in yeast (NEFF and BuRke 1992). It is also unclear whether the spore inviability patterns observed in TP100 reflect recombination and segregation of a dicentric chromosome or recombination and segregation of another type of chromosomal rearrangement (such as a heterozygous translocation). We also do not know whether there are chromosome aberrations in RCY308-10d:CR19, in addition to the one involving chromosomes XV and V.

Physical and genetic analysis of a class 2 strain with a circular chromosome (RCY308-10d:CR18): In RCY30810d:CR18, $V_{L}$ sequences were fused to $\operatorname{poly}\left(\mathrm{G}_{1-3} \mathrm{~T}\right)$ sequences derived from $V_{R}$ (Figure $2 b$ ). Such a fusion should result in a circular chromosome $\mathrm{V}$. This conclusion was confirmed by two types of analysis. First, we examined chromosome V using a CHEF gel (Figure 5c). Although chromosome V from RCY308-10d:CR2 had the expected mobility (lane 1 ), chromosome $\mathrm{V}$ from 


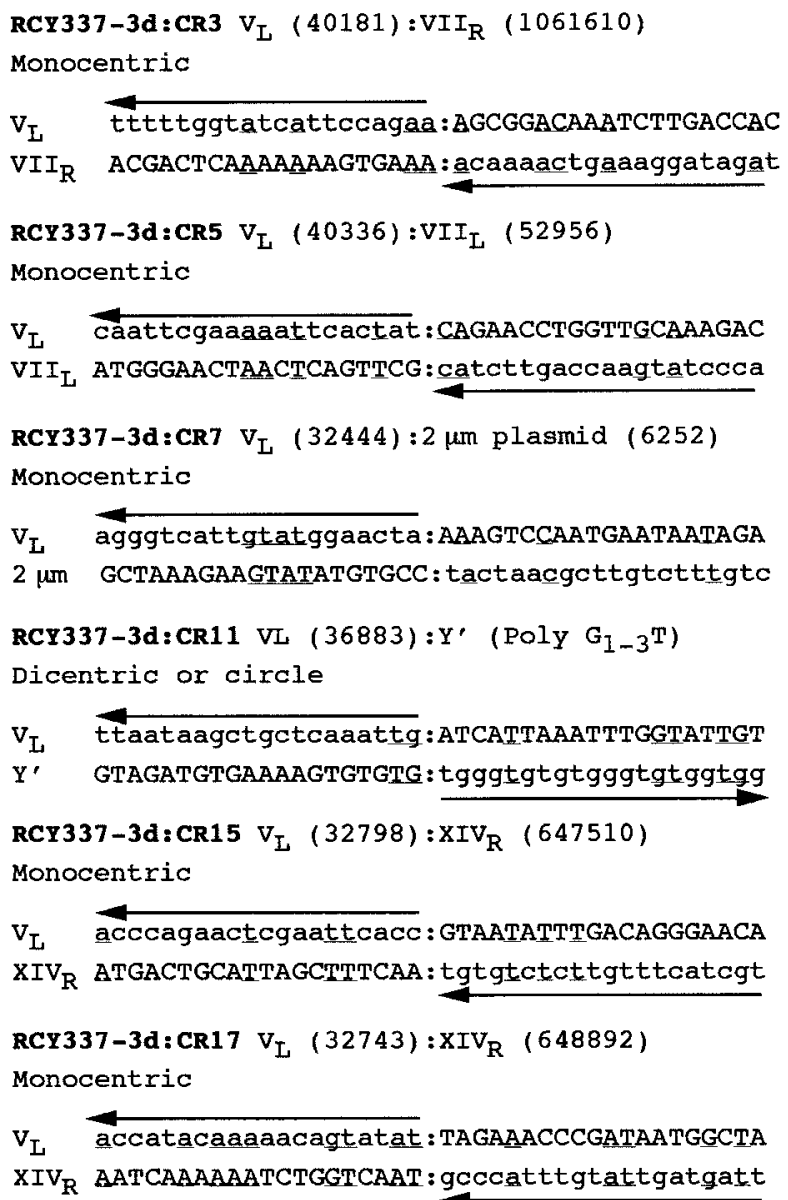

b

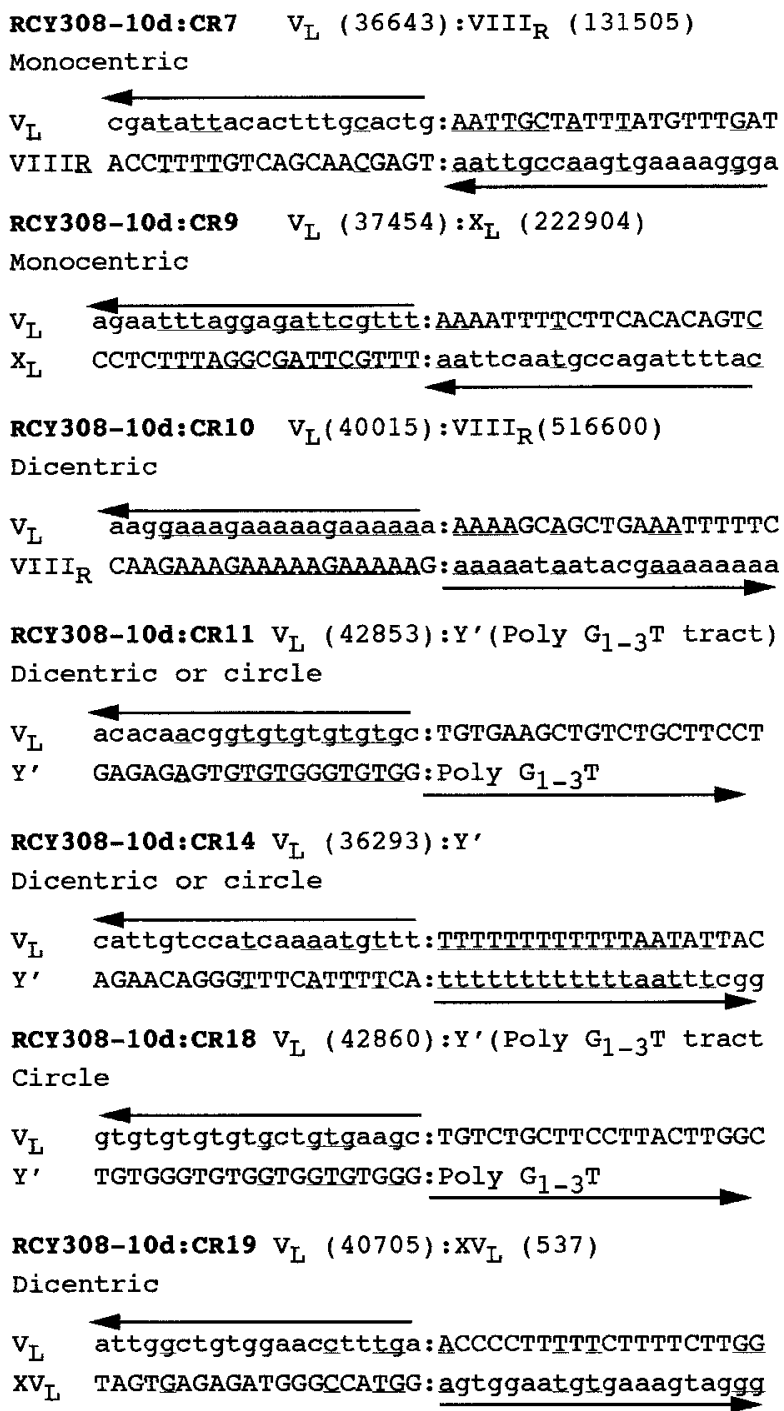

FIGURE 2.-DNA sequences at translocation/fusion breakpoints in canavanine-resistant mutants derived from tel1 mec1 strains. Using methods described in the text, we determined the DNA sequences at the breakpoints between chromosome $\mathrm{V}_{\mathrm{L}}$ sequences and DNA sequences derived from other chromosomes. Numbers in parentheses indicate the position of the breakpoint on each of the two homologs (based on DNA sequence information from the Stanford Genome Database). Arrows indicate the orientation of the chromosomal DNA sequences before the fusion event and point toward the telomeres. Capital letters indicate the sequences found in the fusion fragment. Underscored letters show sequence identities. (a) DNA sequences derived from fusion fragments in RCY337-3d (tel1 mec1- $\Delta$ sml1- $\Delta$ ). (b) DNA sequences derived from fusion fragments in RCY308-10d (tel1 mec1-21).

RCY308-10d:CR18 remained trapped in the loading well (lane 2). The same membrane was rehybridized to a chromosome VIII-specific probe (lanes 3 and 4) to demonstrate that other chromosomes in RCY308-10d:CR18 had the expected mobility. Since the trapping of circular yeast chromosomes in gel wells during OFAGE has been described previously by GAME et al. (1989), this result is consistent with the presence of a circular chromosome in RCY308-10d:CR18.

We also performed a standard Southern analysis using a $\mathrm{V}_{\mathrm{R}}$-specific probe (described in MATERIALS AND METHoDs) that was located in single-copy sequences immediately centromere proximal to the $\mathrm{X}$ and $\mathrm{Y}^{\prime}$ telomeric repeats. The expected (Figure 6a) and observed (Figure 6b) sizes of the restriction fragments for a circular chromosome were in good agreement. The confirmation of the SfiI site near the $\mathrm{V}_{\mathrm{L}}-\mathrm{V}_{\mathrm{R}}$ junction is a particularly convincing argument, since SfiI cuts very infrequently in the yeast genome (LINK and Olson 1991). In addition, since RCY308-10d:CR18 lacks the DNA fragments characteristic of the wild-type $V_{R}$, the chromosome rearrangement does not represent a $V_{R}-V_{L}$ fusion between two linear copies of chromosome V. It should be noted that, although the strongest band of hybridization in the control strain is at the position expected for the $V_{R}$ telomere (which has a single $\mathrm{Y}^{\prime}$ element), there is a 
weak band of hybridization at approximately the size expected for a $V_{R}$ telomere with two $\mathrm{Y}^{\prime}$ elements. It is likely that the population of cells used for Southern analysis of the control strain had a small number of cells with a double $\mathrm{Y}^{\prime}$ element. Such $\mathrm{Y}^{\prime}$ amplification events have been observed previously in tel1 mec1 strains (Ritchie et al. 1999).

We also crossed RCY308-10d:CR18 to the wild-type a

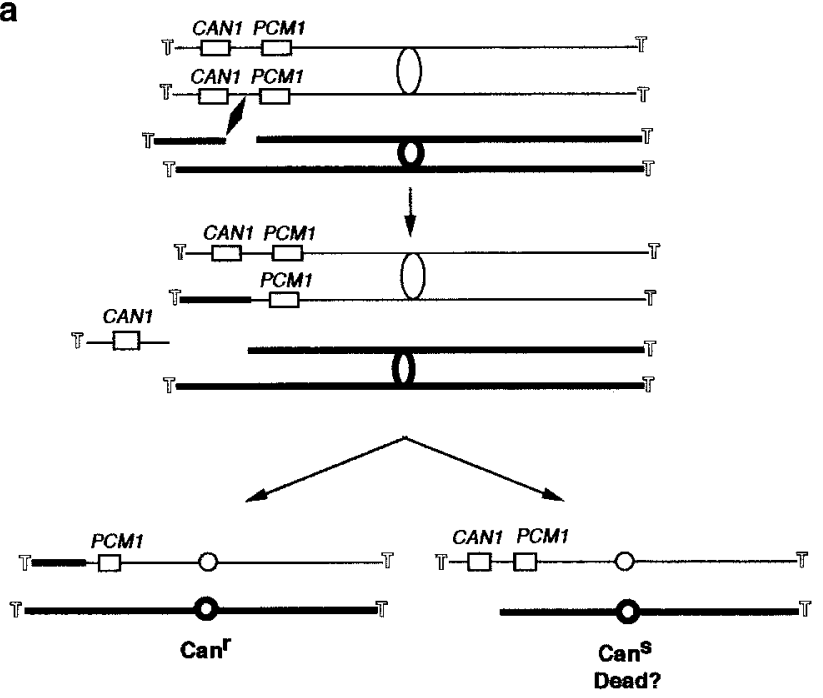

C

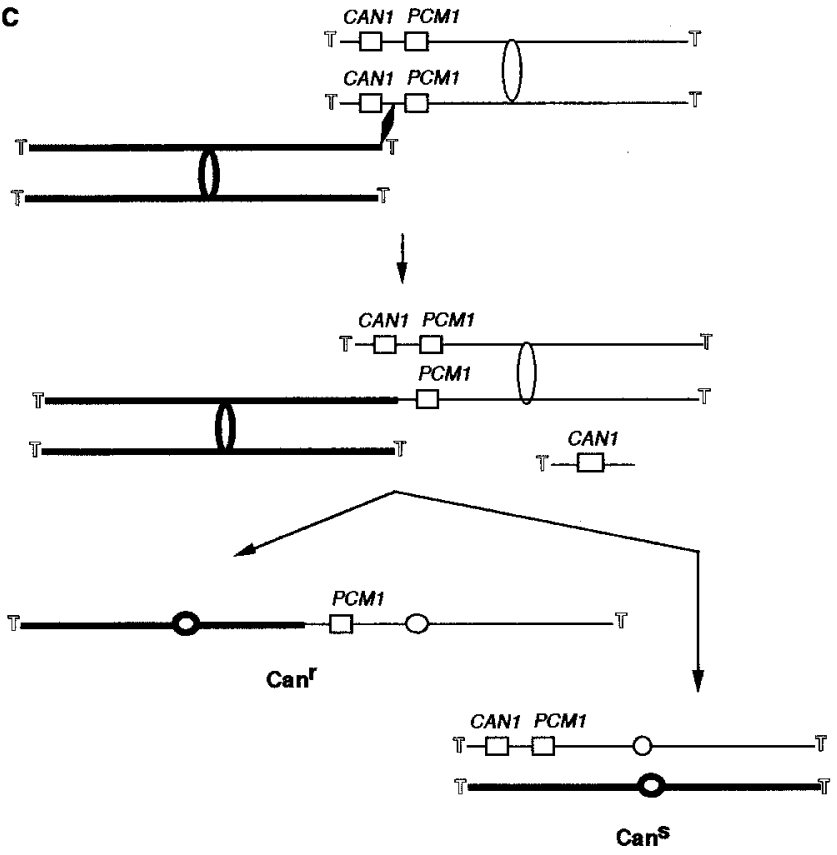

b
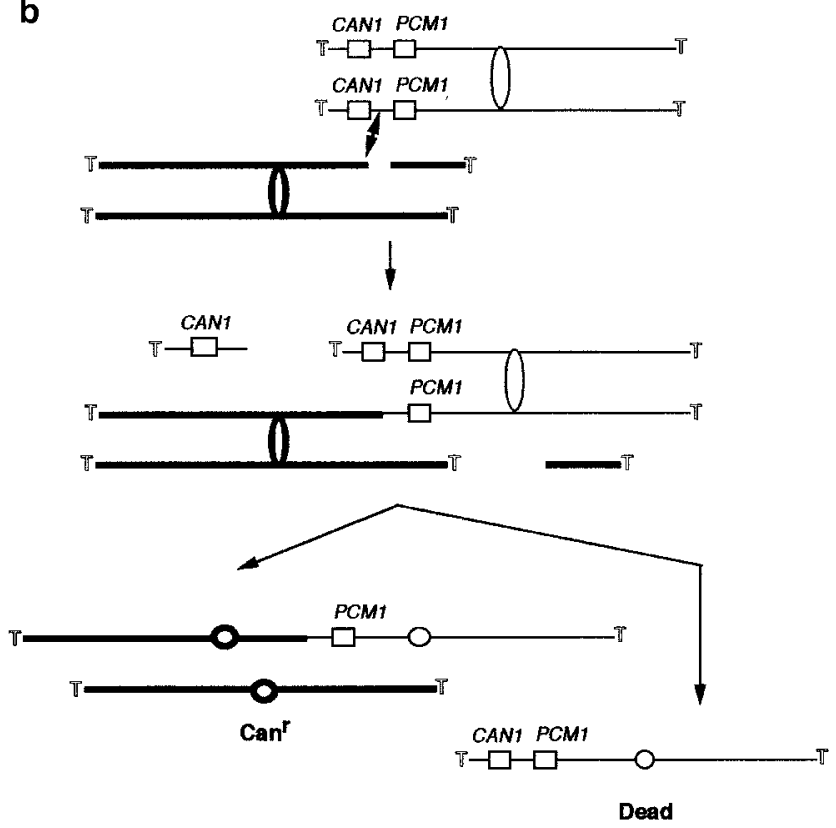

d

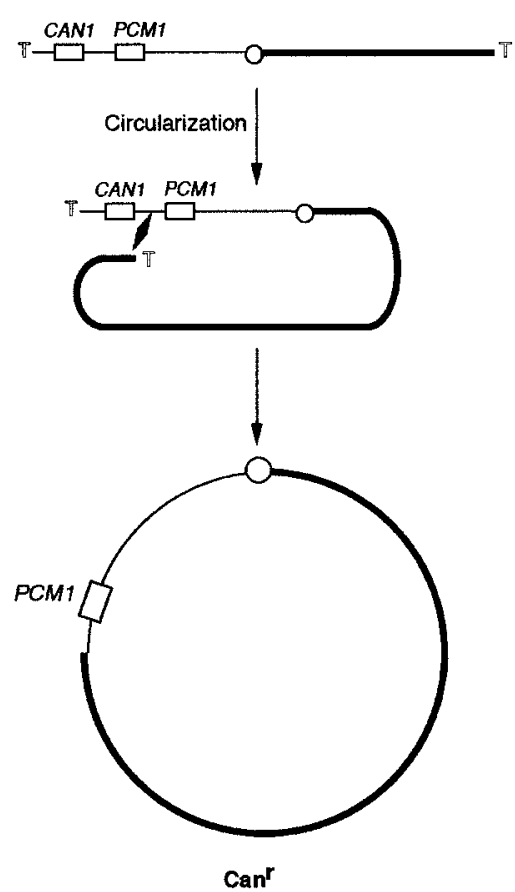

FigurE 3.-Chromosome alterations leading to loss of CAN1 and distal DNA sequences. In a-c, chromosome V sequences are shown by thin lines (centromeres indicated by circles) and sequences from a nonhomologous chromosome are shown by thick lines; $\mathrm{T}$ indicates the telomeres. In a-c, the double-strand break that initiates exchange is on the nonhomologous chromosome and the double-headed arrows show the position of the exchange. We assume that the event is nonreciprocal and that DNA sequences that are unattached to centromeres are not stably maintained. In $d$, the $\mathrm{V}_{\mathrm{L}}$ sequences are shown by thin lines, and the $V_{R}$ sequences are represented by thick lines. For each event, only the canavanine-resistant derivative is selectable. All recombination events are assumed to involve little or no DNA sequence homology (consistent with the sequence analysis of breakpoints in Figure 2). (a) Loss of CAN1 as a consequence of formation of two monocentric translocations. (b) Loss of CAN1 as a consequence of formation of a single dicentric translocation. (c) Loss of CAN1 as a consequence of a fusion between $\mathrm{V}_{\mathrm{L}}$ sequences and telomeric repeats derived from a nonhomologous chromosome. (d) Loss of CAN1 as a consequence of a fusion between $V_{L}$ sequences and telomeric repeats derived from $V_{R}$. 
a
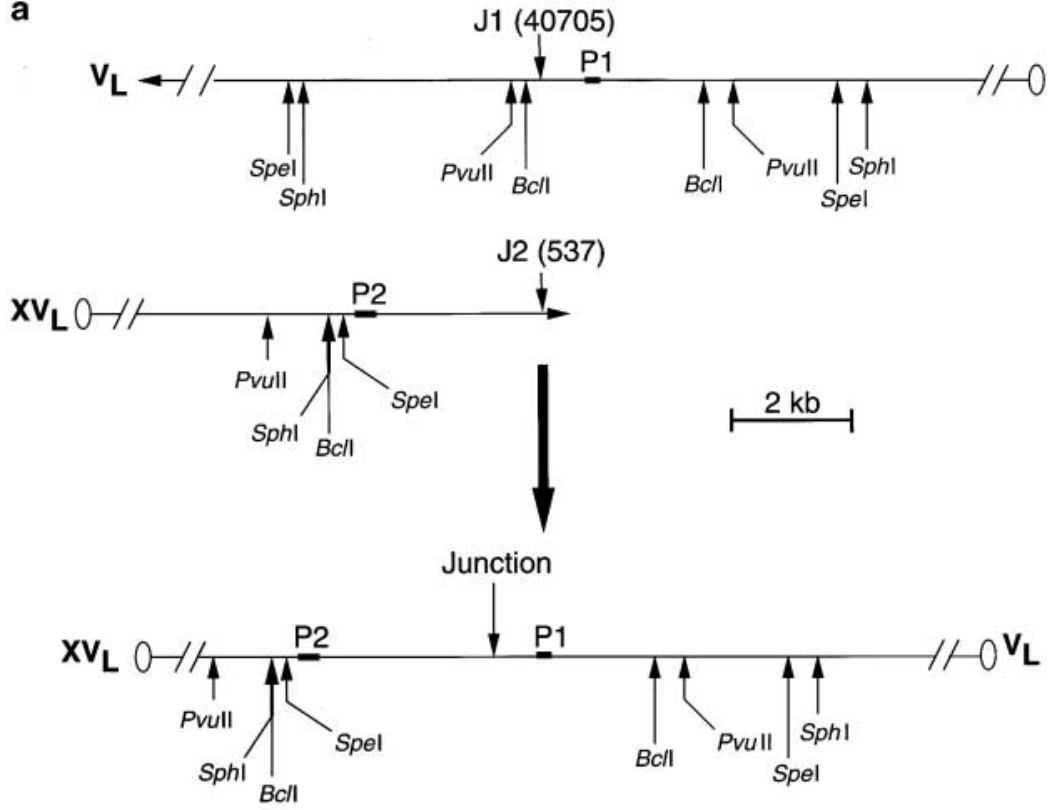

b

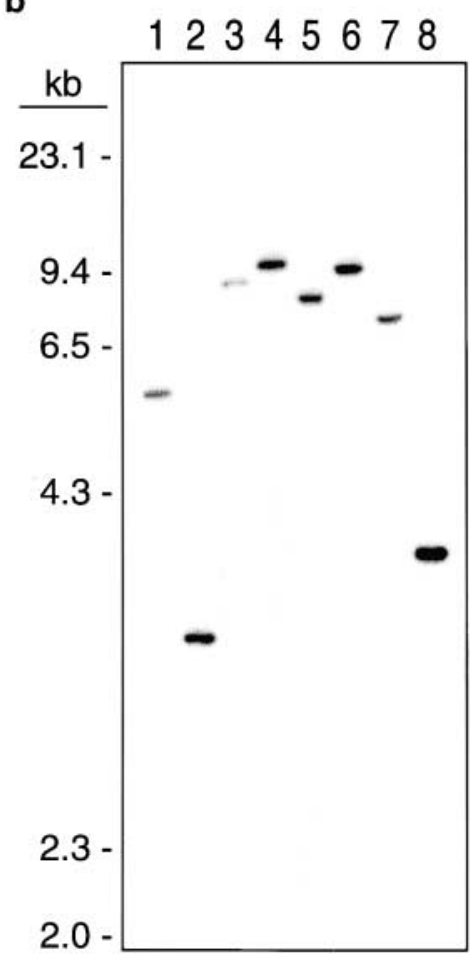

C

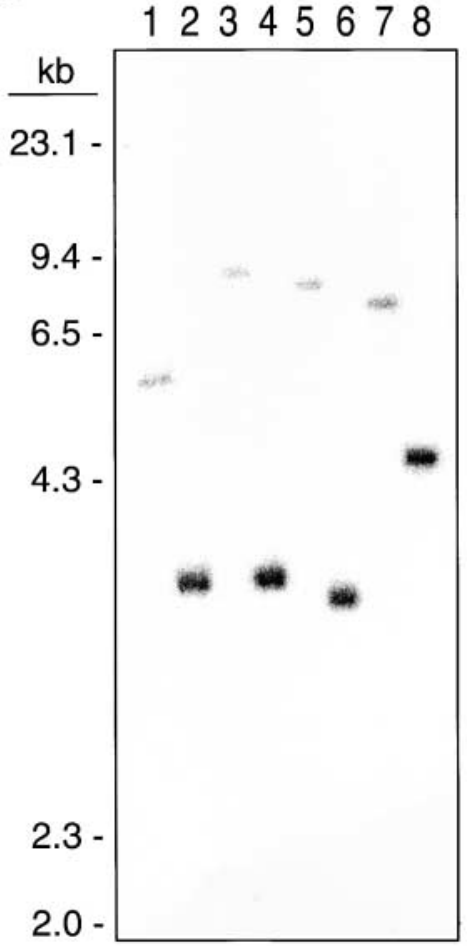

Figure 4.-Southern analysis of DNA isolated from RCY308-10d:CR19, a strain with a fusion between $V_{L}$ and $X V_{L}$ sequences, and RCY308-10d (control strain from which RCY308-10d:CR19 was derived). The DNA sequences at the breakpoint of the rearrangement in RCY308-10d:CR19 indicated a fusion at position 40705 of $\mathrm{V}_{\mathrm{L}}$ and 537 of $\mathrm{XV}_{\mathrm{L}}$ (within the subtelomeric $\mathrm{X}$ repeat of $\mathrm{XV}$ ). $\mathrm{P} 1$ and $\mathrm{P} 2$ represent the positions of $\mathrm{V}_{\mathrm{L}^{-}}$and $\mathrm{XV}_{\mathrm{L}^{-}}$ specific probes, respectively (probes described in MATERIALS AND METHODS). (a, top) Restriction maps of regions of the unrearranged $V_{L}$ and $X V_{L}$ chromosomes derived from Stanford Genome Database. ( $\mathrm{a}$, bottom) Expected restriction map from the fusion chromosome. (b and c) Southern analysis of DNA from RCY308-10d:CR19 (oddnumbered lanes) and RCY308-10d (even-numbered lanes) using P1 (b) and P2 (c) probes. In both $\mathrm{b}$ and $\mathrm{c}$, the restriction enzymes used were $B c l$ I (lanes 1 and 2), SphI (lanes 3 and 4), SpeI (lanes 5 and 6), and PvuII (lanes 7 and 8). Note that the hybridization bands in DNA of RCY30810d:CR19 are at the same positions in gels probed with P1 and P2. haploid strain DFS188 and examined the viability of spores of the resulting diploid strain (MD150). The percentages of tetrads with $4,3,2,1$, and 0 viable spores were $7,13,31,32$, and 17 , respectively; the total spore viability was $40 \%$. Thus, compared to the control diploid strain (TPY101, described above), there was a significant loss of spore viability. This type of inviability is expected in strains heterozygous for a circular chromosome, since meiotic recombination events between a linear and circular chromosome would be expected to result in forma- tion of dicentric chromosomes and acentric fragments (HABER et al. 1984).

\section{DISCUSSION}

Strains with the double tel1 mecl genotype have a much stronger phenotype than that observed in strains with the tel1 or mec1 single mutations in a variety of assays of genome stability. The specific assays for genome stability that have been used include sensitivity 


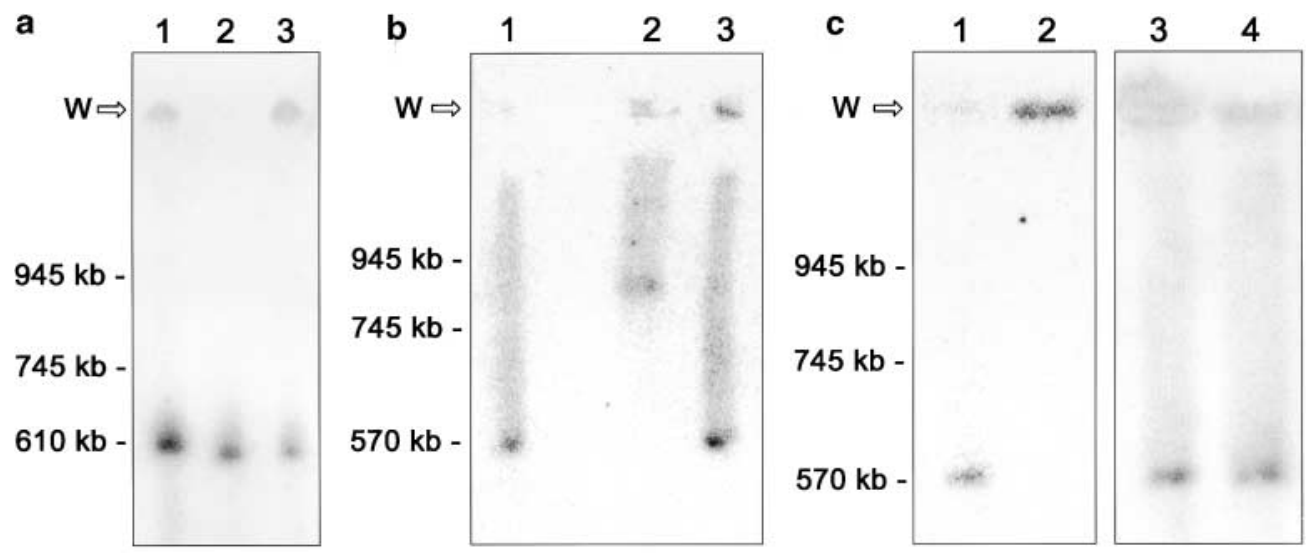

Figure 5.-Analysis of chromosome V in strains RCY30810d:CR2, RCY308-10d:CR18, and RCY308-10d:CR19. Intact chromosomes were examined by gel electrophoresis, using either TAFE (a) or CHEF (b and c) gels. The size standards were commercially available marker yeast chromosomes from New England Biolabs. Following gel electrophoresis, DNA molecules were transferred to nylon membranes and hybridized to chromosome-specific probes [YIp5 for chromosome $\mathrm{V}$ and a PCR

fragment containing ARG4 sequences for chromosome VIII (primer sequences given in MATERIALS AND METHODS)]. (a) Gel analysis of chromosome V from strain YPH80 (lane 1, marker chromosomes), W303a (lane 2, control wild-type strain), and RCY308-10d:CR2 (lane 3, canavanine-resistant derivative with point mutation in CAN1). (b) Analysis of chromosome V from RCY308-10d (lane 1, control tel1 mec1-21 strain), RCY308-10d:CR19 (lane 2, V/XV translocation), and RCY308-10d:CR2 (lane 3). (c) Analysis of chromosomes V and VIII from RCY308-10d:CR2 (lanes 1 and 3) and RCY308-10d:CR18 (lanes 2 and 4). The nylon filter was first hybridized with the chromosome V-specific probe (lanes 1 and 2) and then stripped and reprobed with the chromosome VIII-specific probe (lanes 3 and 4).

to DNA damaging agents (Morrow et al. 1995; Usur et al. 2001); measurements of telomere length and the rates of cellular senescence (RitchiE et al. 1999); rates of deletions and other gross chromosomal rearrangements (MYung et al. 2001b); and rates of chromosome loss, mitotic recombination, and forward mutation rates (as reported above).

The elevated levels of mitotic recombination and chromosome loss observed in tel1 mec1 strains suggest high levels of DNA damage. There are two nonexclusive explanations for the elevated rates of DNA damage. First, wild-type yeast strains may have intrinsically high levels of spontaneous DNA damage, but this level of DNA damage is efficiently repaired by a Mec1p-/Tellpdependent mechanism. Second, the tel1 mecl strains may have a type of DNA damage that is not observed in wild-type strains. Although both of these mechanisms may contribute to the genomic instability observed in tel1 mec1 strains, on the basis of the types of chromosome alterations observed in the canavanine-resistant mutants derived in the tel1 mecl genetic background, we favor the second explanation.

What types of DNA damage could be responsible for the elevated level of genome instability in tel1 mec1 strains? We suggest that there are two types leading to two classes of genome instability. First, the loss of telomeric repeats in tel1 mec1 strains results in the recognition of the telomeres as double-stranded DNA breaks (DSBs) that require repair. Use of telomeres as recombination substrates could result in formation of chromosome aberrations such as those shown in Figure 3, c and d. A similar hypothesis was previously used by MCEACHERN and IYER (2001) to explain the elevated levels of recombination of subtelomeric sequences in Kluyveromyces lactis strains with short telomeres. Second, we postulate that tel1 mec1 strains have elevated levels of DSBs throughout the ge- nome. These DSBs could generate the types of chromosome aberrations shown in Figure 3, a and b. Consistent with this possibility, strains with mec1 (TERCERo and Diffley 2001) and rad53 (Lopes et al. 2001) mutations are defective in maintaining blocked DNA replication forks, and it has been suggested that aberrant processing of blocked replication forks may lead to DSBs (Lopes et al. 2001). In addition, Merrill and Holm (1999) showed accumulated single-stranded DNA synthesis intermediates in mecl strains and suggested that these intermediates would be processed into double-stranded DNA breaks during DNA replication.

Our studies are in good agreement with the very high rate of GCRs observed in tell mec1 cells and the low rate of GCR seen in tlc1 cells (MyUnG et al. 2001a,b). HACKETT et al. (2001) recently showed that yeast strains with a mutation in est 1 had elevated levels of mutations in the CAN1 assay and high levels of chromosome rearrangments. Although the tlc1 mutation used in our study and that of Myung et al. (2001a,b) would be expected to result in a similar phenotype as the est 1 mutation used by Hackett $e t$ al., one difference is that our experiments were performed with survivors, whereas those of Hackett $e t$ al. were done with $e s t 1$ cells at various stages of the senescence process. They found that the est 1 mutator phenotype was strongest in the cells that were growing poorly, and much of this phenotype was lost after survivors were generated. Since the experiments of Myung et al. (2001a,b) were done with tlc1 strains prior to the onset of survivors, however, there appears to be a significant difference in genomic instability in tlc1 and est 1 strains.

Although tel1 mec1 strains have elevated rates of several types of genomic instability, the absolute rates of instability are quite different for the different assays (Tables 2 and 3): rates (events per cell division) of about 


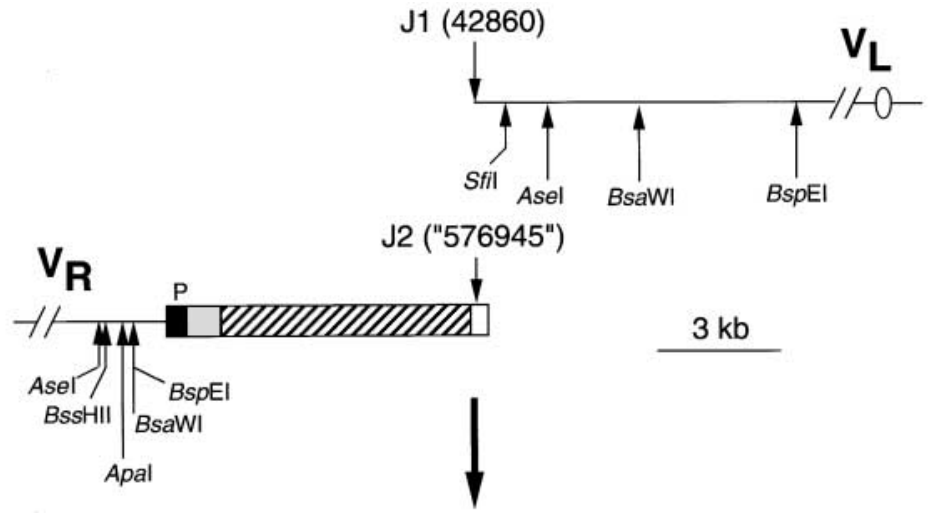

FIGURE 6.-Southern analysis of DNA isolated from RCY308-10d:CR18, a strain with a circular derivative of chromosome $\mathrm{V}$. (a) The placement of the restriction sites is based on information in the Stanford Genome Database. In addition to the depicted restriction sites, $A p a \mathrm{I}$ and BssHII cut 19 and $57.3 \mathrm{~kb}$, respectively, centromere proximal to J1; Sfil cuts $392 \mathrm{~kb}$ centromere proximal to J2. The coordinate for the J2 junction indicated in parentheses is an extrapolation of the information in SGD, since the full sequence of chromo-

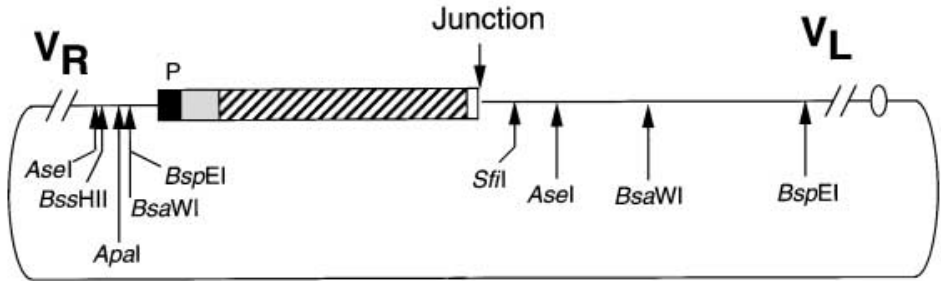
some $V_{R}$ is not present. The subtelomeric repeats of $\mathrm{X}$ and $\mathrm{Y}^{\prime}$ are shown as shaded and hatched rectangles, respectively. The terminal poly $\left(\mathrm{G}_{1-3} \mathrm{~T}\right)$ tract is shown as an open rectangle and the hybridization probe is indicated by a solid rectangle. (b) Southern blot of DNA isolated from RCY30810d:CR18 (odd-numbered lanes) and the control strain RCY308-10d (even-numbered lanes) hybridized to a $V_{R}$-specific probe (indicated by $P$ in a). Restriction enzymes used in the analysis were:

b

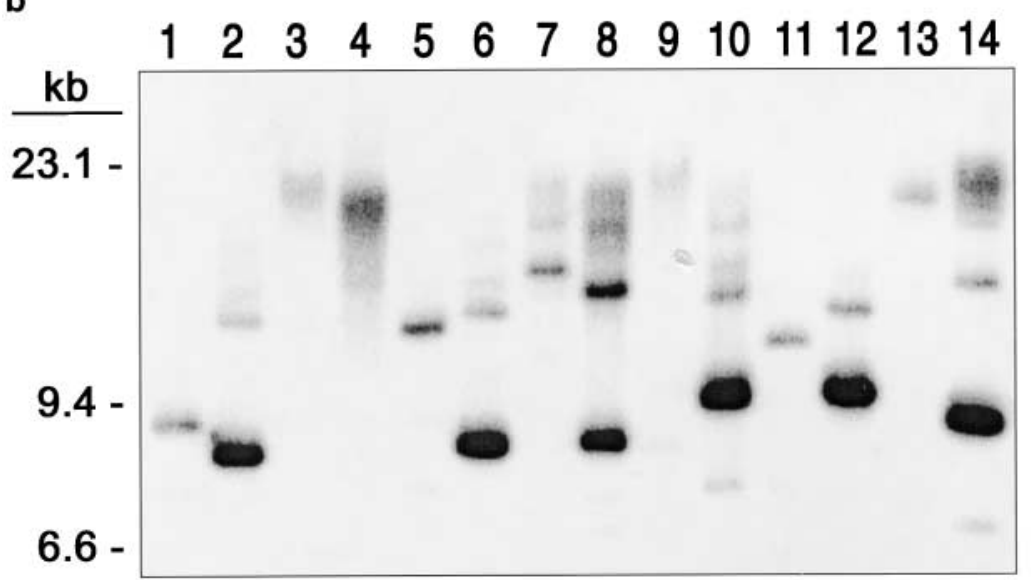
$B s s \mathrm{WI}+$ Sfi (lanes 1 and 2), SfiI (lanes 3 and 4), $B s a W I$ (lanes 5 and 6), BspEI (lanes 7 and 8), BssHII (lanes 9 and 10), AseI (lanes 11 and 12), and ApaI (lanes 13 and 14). The expected sizes of DNA fragments if RCY308-10d:CR18 has a circular chromosome (observed sizes in parentheses) are: BsaWI + Sfil, $8.9 \mathrm{~kb}(9 \mathrm{~kb})$; Sfil, $392 \mathrm{~kb}$ (>20 kb); $B s a W I, 12.2 \mathrm{~kb}(11.5 \mathrm{~kb})$; BspEI, $16.1 \mathrm{~kb}$ (15 kb); BssHII, $66.5 \mathrm{~kb}$ (>20 kb); AseI, $11.1 \mathrm{~kb}$ (12 kb); and $A p a \mathrm{I}, 27.7 \mathrm{~kb}(>20 \mathrm{~kb})$. The expected sizes of the DNA fragments for RCY308-10d (observed sizes in parentheses) are: $B s a \mathrm{WI}+S f \mathrm{I}, 8.5 \mathrm{~kb}(8.2 \mathrm{~kb})$; Sfil, $392 \mathrm{~kb}(>20 \mathrm{~kb})$; BsaWI, $8.5 \mathrm{~kb}(8.2 \mathrm{~kb})$; BspEI, $8.5 \mathrm{~kb}(8.2 \mathrm{~kb})$; BssHII, $9.5 \mathrm{~kb}(9.3 \mathrm{~kb})$; AseI, $9.7 \mathrm{~kb}(10 \mathrm{~kb})$; and $A p a \mathrm{I}, 8.9 \mathrm{~kb}(8.8 \mathrm{~kb})$. (c) Southern blot of DNA isolated from RCY30810d:CR18 (odd-numbered lanes) and the control strain RCY308-10d (even-numbered lanes) hybridized to a $\mathrm{Y}^{\prime}$-specific probe. The same samples used in $b$ were treated with the same restriction

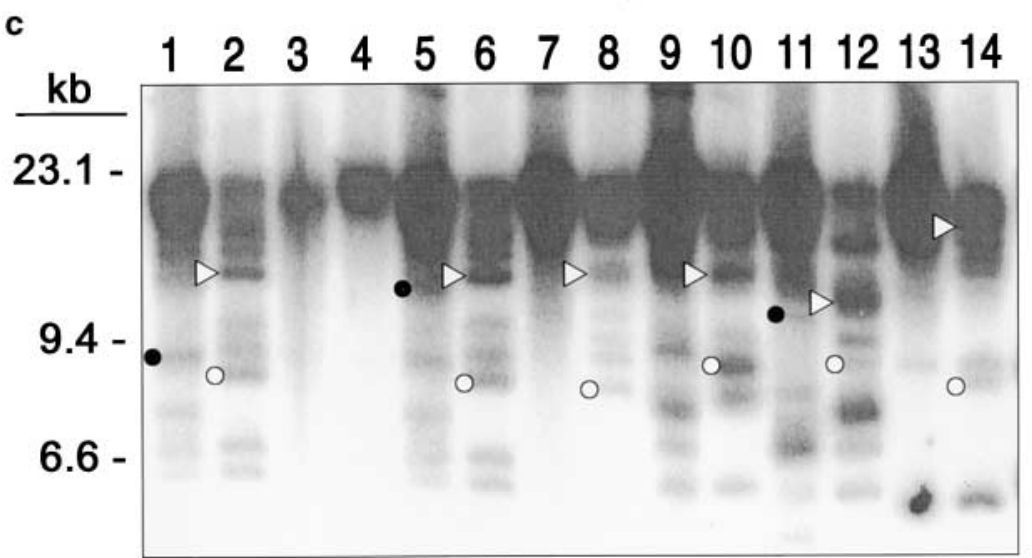
enzymes and loaded in the same order on the gel. The bands shown as black dots in lanes containing RCY308-10d:CR18 are the sizes expected for the circular chromosome V. Lanes marked with open circles are the sizes expected for the linear chromosome $\mathrm{V}$. The bands marked with triangles are approximately the sizes expected for integration of a second $Y^{\prime}$ at $V_{R}$ in a subset of cells with a linear chromosome $\mathrm{V}$; their sizes also correspond to those of some of the weakly hybridizing bands observed in $\mathrm{b}$.

$10^{-3}$ for chromosome loss, $10^{-4}$ for mitotic recombination, and $10^{-5}$ for mutations. Although the tel1 mec1-21 and tel1 mec1- $\Delta$ sml1 strains have similar rates of mitotic recombination and chromosome loss, mutation rates in the tel1 mec1- $\Delta$ sml1 strain are about fourfold higher than those observed in the tel1 mec1-21 strain. One inter- 
pretation is that the tell mec1- $\Delta$ sml1 strain may have a slightly reduced ability (relative to the tel1 mec1-21 strain) to repair DNA breaks by homologous recombination pathways and, consequently, exhibit an elevation in repair by the NHEJ pathway associated with production of the chromosomal rearrangements. Since the rate of homologous mitotic recombination is much higher than the mutation rate at $C A N 1$, an undetectable change in the mitotic recombination rate could substantially elevate the rate of mutation. Alternatively, compared to the tel1 mec1-21 strain, the tel1 mec1- $\Delta$ sml1 strain may have elevated levels of DNA damage that can be repaired only by the NHEJ pathway.

It should be emphasized that some of the chromosome aberrations that we have observed would be expected to generate repeated cycles of chromosome rearrangements. For example, dicentric chromosomes, as a consequence of segregation problems during mitosis, may generate double-strand breaks at random positions. Such breaks would be expected to stimulate secondary rounds of mitotic recombination and chromosome loss. This type of mechanism has also been invoked by HAckETT et al. (2001) to explain chromosome rearrangments observed in yeast strains with an est 1 mutation. Circular chromosomes, such as that demonstrated in RCY30810d:CR18, would also be expected to be a source of genome instability. Recombination between circular and linear chromosomes either in meiosis or in mitotic diploid cells would produce dicentric linear chromosomes, and sister-sister strand recombination events would produce dicentric circular chromosomes.

Several more points concerning the comparison of tel1 mec1 and tlc1/est1 phenotypes should be mentioned. First, we observed a class 2 mutant in the $t l c 1$ strain (Table 4), suggesting that chromosome rearrangements may occur in this genetic background. Second, since most of the mutants observed in the $t l c 1$ survivors were point mutations (Table 4), there is a mutator phenotype associated with the telomerase-negative strain that is independent of chromosomal alterations. It is possible that $t l c 1$ strains accumulate DNA damage that is repaired by error-prone DNA polymerases, although other explanations for the mutator phenotype also exist.

Our results indicate that the cell death observed in tel1 mec1 strains may involve more than a single mechanism. One mechanism may be loss of essential genes located near the telomere as a consequence of end-directed DNA degradation. A second mechanism may reflect the constant generation of DNA damage as a consequence of repeated cycles of breakage of dicentric chromosomes. As mentioned in the Introduction, mutations in ATM and ATR also lead to increased levels of endto-end chromosome fusions, mitotic recombination, and chromosome breakage (MeYn 1993; PANDita et al. 1995; Brown and Baltimore 2000). Thus, the ATM family of protein kinases safeguards multiple aspects of chromosome stability in very different organisms.
We thank R. Rothstein, H. Klein, J. Mallory, K. Ritchie, and L. M. Curtis for strains used in the study and H. Klein, D. Gottschling, K. Myung, and R. Kolodner for communication of unpublished results and comments on the manuscript. We thank L. M. Curtis and L. Stefanovich for help with strain constructions, R. Kokoska and J. Merker for advice about data analysis, and K. Lobachev for help with the OFAGE analysis. The research was supported by National Institutes of Health grants to T.D.P. (GM-24110 and GM-52319) and R.J.C. (Building Interdisciplinary Research Careers in Women's Health scholar).

\section{LITERATURE CITED}

Brown, E. J., and D. BAltimore, 2000 ATR disruption leads to chromosomal fragmentation and early embryonic lethality. Genes Dev. 14: 397-402.

Brush, G. S., D. M. Morrow, P. Hieter and T. J. Kelly, 1996 The ATM homologue MEC1 is required for phosphorylation of replication protein A in yeast. Proc. Natl. Acad. Sci. USA 93: 1507515080 .

Carr, A. M., 1997 Control of cell cycle arrest by the $\operatorname{Mec}^{\text {sc }} / \operatorname{Rad} 3^{\text {sp }}$ DNA structure checkpoint pathway. Curr. Opin. Genet. Dev. 7: 93-98.

Chen, C., and R. D. Kolodner, 1999 Gross chromosomal rearrangements in Saccharomyces cerevisiae replication and recombination defective mutants. Nat. Genet. 23: 81-85.

Chen, C., K. Umezu and R. D. Kolodner, 1998 Chromosomal rearrangements occur in S. cerevisiae mutator mutants due to intergenic lesions processed by double-strand-break repair. Mol. Cell 2: 9-22.

Counter, C. M., A. A. Avilon, C. E. Lefeuvre, N. G. Stewart, C. W. Greider et al., 1992 Telomere shortening associated with chromosome instability is arrested in immortal cells which express telomerase activity. EMBO J. 11: 1921-1929.

Craven, R. J., and T. D. Petes, 1999 Dependence of the regulation of telomere length on the type of subtelomeric repeat in the yeast Saccharomyces cerevisiae. Genetics 152: 1531-1541.

Craven, R. J., and T. D. Petes, 2000 Involvement of the checkpoint protein Mec1p in silencing of gene expression at telomeres in Saccharomyces cerevisiae. Mol. Cell. Biol. 20: 2378-2384.

Craven, R. J., and T. D. Petes, 2001 The Saccharomyces cerevisiae suppressor of choline sensitivity (SCS2) gene is a multicopy suppressor of mec1 telomeric silencing defects. Genetics 158: 145154.

Desany, B. A., A. A. Alcasabas, J. B. Bachant and S. J. Elledge, 1998 Recovery from DNA replication stress is the essential function of the S-phase checkpoint pathway. Genes Dev. 12: 29562970.

Fan, H. Y., K. K. Cheng and H. L. Klein, 1996 Mutations in the RNA polymerase II transcription machinery suppress the hyperrecombination mutant hprls of Saccharomyces cerevisiae. Genetics 142: 749-759.

Game, J. C., K. C. Sitney, V. E. Cook and R. K. Mortimer, 1989 Use of a ring chromosome and pulse-field gels to study interhomolog recombination, double-strand DNA breaks and sister-chromatid exchange in yeast. Genetics 123: 695-713.

Greenwell, P. W., S. L. Kronmal, S. E. Porter, J. Gassenhuber, B. Obermaier et al., 1995 TEL1, a gene involved in controlling telomere length in $S$. cerevisiae, is homologous to the human Ataxia telangiectasia gene. Cell 82: 823-829.

Grushcow, J. M., T. M. Holzen, K. J. PARK, T. Weinert, M. Lichten $e t$ al., 1999 Saccharomyces cerevisiae checkpoint genes MEC1, RAD17 and $R A D 24$ are required for normal meiotic recombination partner choice. Genetics 153: 607-620.

Guthrie, C., and G. R. Fink (Editors), 1991 Guide to Yeast Genetics and Molecular Biology. Academic Press, San Diego.

Haber, J. E., P. C. Thorburn and D. Rogers, 1984 Meiotic and mitotic behavior of dicentric chromosomes in Saccharomyces cerevisiae. Genetics 106: 185-205.

Hackett, J. A., D. M. Feldser and C. W. Greider, 2001 Telomere dysfunction increases mutation rate and genomic instability. Cell 106: 275-286.

Harley, C. B., 1995 Telomeres and aging, pp. 247-263 in Telomeres, 
edited by E. H. Blackburn and C. W. Greider. Cold Spring Harbor Laboratory Press, Cold Spring Harbor, NY.

Hartwell, L. H., and D. Smith, 1985 Altered fidelity of mitotic chromosome transmission in cell cycle mutants of $S$. cerevisiae. Genetics 110: 381-395.

Hayflick, L., and P. S. Moorhead, 1961 The serial cultivation of human diploid cell strains. Exp. Cell Res. 25: 585-621.

Kato, R., and H. Ogawa, 1994 An essential gene, ESR1, is required for mitotic cell growth, DNA repair and meiotic recombination in Saccharomyces cerevisiae. Nucleic Acids Res. 22: 3104-3112.

Keith, C. T., and S. L. Schreiber, 1999 PIK-related kinases: DNA repair, recombination, and cell cycle checkpoints. Science 270: $50-51$.

Kuein, H. L., 2001 Spontaneous chromosome loss in Saccharomyces cerevisiae suppressed by DNA damage checkpoint functions. Genetics 159: 1501-1509.

Kokoska, R., L. Stefanovic, J. Demai and T. D. Petes, 2000 Increased rates of genomic deletions generated by mutations in the yeast gene encoding DNA polymerase $\delta$ or by decreases in cellular levels of DNA polymerase $\delta$. Mol. Cell. Biol. 20: 74907504 .

LeA, D. E., and C. A. Coulson, 1949 The distribution of the number of mutants in bacterial populations. J. Genet. 49: 264-285.

Lengauer, C., K. W. Kinzler and B. Vogelstein, 1998 Genetic instabilities in cancer. Nature 386: 623-627.

Link, A. J., and M. V. OLson, 1991 Physical map of the Saccharomyces cerevisiae genome at 110-kb resolution. Genetics 127: 681-698.

Lopes, M., C. Cotta-Ramusino, A. Pellicioli, G. Liberi, P. Plevani et al., 2001 The DNA replication checkpoint response stabilizes stalled replication forks. Nature 412: 557-561.

Lowndes, N. F., and J. R. Murguia, 2000 Sensing and responding to DNA damage. Curr. Opin. Genet. Dev. 10: 17-25.

Lundblad, V., and E. BlackbuRn, 1993 An alternative pathway for telomere maintenance rescues est 1 -senescence. Cell 73: 347-360.

Lustig, A. J., and T. D. Petes, 1986 Identification of yeast mutants with altered telomere structure. Proc. Natl. Acad. Sci. USA 83: 1389-1402.

Lydall, D., Y. Nikolsky, D. K. Bishop and T. Weinert, 1996 A meiotic recombination checkpoint controlled by mitotic checkpoint genes. Nature 383: 840-843.

Mallory, J. C., and T. D. Petes, 2000 Protein kinase activities of Tellp and Meclp, two S. cerevisiae proteins related to the human ATM kinase. Proc. Natl. Acad. Sci. USA 97: 13749-13754.

McAinsh, A. D., S. Scott-Drew, J. A. Murray and S. P. Jackson, 1999 DNA damage triggers disruption of telomeric silencing and Meclp-dependent relocation of Sir3p. Curr. Biol. 9: 963-966.

McEachern, M. J., and S. Iyer, 2001 Short telomeres in yeast are highly recombinogenic. Mol. Cell 7: 695-704.

Merrill, B. J., and C. Holm, 1999 A requirement for recombinational repair in Saccharomyces cerevisiae is caused by DNA replication defects of mec1 mutants. Genetics 153: 595-605.

Meyn, M. S., 1993 High spontaneous intrachromosomal recombination rates in ataxia-telangiectasia. Science 260: 1327-1330.

Mills, K. D., D. A. Sinclair and L. Guarente, 1999 MEC1-dependent redistribution of the Sir3 silencing protein from telomeres to DNA double-strand breaks. Cell 97: 609-620.

Mikus, M., and T. D. Petes, 1982 Recombination between genes located on non-homologous chromosomes in the yeast Saccharomyces cerevisiae. Genetics 101: 369-404.

Morrow, D. M., D. A. Tagle, Y. Shiloh, F. S. Collins and P. Hieter, 1995 TEL1, an S. cerevisiae homologue of the human gene mutated in Ataxia Telangiectasia, is functionally related to the yeast checkpoint gene MEC1. Cell 82: 831-840.

Myung, K., C. Chen and R. D. Kolodner, 2001a Multiple pathways cooperate in the suppression of genome instability in Saccharomyces cerevisiae. Nature 411: 1073-1076.

Myung, K., A. Datta and R. D. Kolodner, 2001b Suppression of spontaneous chromosomal rearrangements by $\mathrm{S}$ phase checkpoint functions in Saccharomyces cerevisiae. Cell 104: 397-408.

Naito, T., A. Matsuura and F. Ishikawa, 1998 Circular chromo- some formation in a fission yeast mutant deficient in two ATM homologues. Nat. Genet. 20: 203-206.

NefF, M. W., and D. J. Burke, 1992 A delay in the Saccharomyces cerevisiae cell cycle that is induced by a dicentric chromosome and dependent upon mitotic checkpoints. Mol. Cell. Biol. 12: $3857-3864$.

Paciotti, V., M. Clerici, G. Lucchini and M. P. Longhese, 2000 The checkpoint protein Ddc2, functionally related to $S$. pombe Rad26, interacts with Mec1 and is regulated by Mec1-dependent phosphorylation in budding yeast. Genes Dev. 14: 2046-2059.

Pandita, T. K., S. Pathak and C. Geard, 1995 Chromosome end associations, telomeres and telomerase activity in ataxia telangiectasia cells. Cytogenet. Cell Genet. 71: 86-93.

PAQues, F., and J. E. HABER, 1999 Multiple pathways of recombination induced by double-strand breaks in Saccharomyces cerevisiae. Microbiol. Mol. Biol. Rev. 63: 349-404.

Ritchie, K. B., and T. D. Petes, 2000 The Mre11p/Rad50p/Xrs2p complex and Tellp function in a single pathway for telomere maintenance in yeast. Genetics 155: 475-479.

Ritchie, K. B., J. C. Mallory and T. D. Petes, 1999 Interactions of TLC1 (which encodes the RNA sub-unit of telomerase), TEL1, and MEC1 in regulating telomere length in the yeast Saccharomyces cerevisiae. Mol. Cell. Biol. 19: 6065-6075.

Sanchez, Y., B. A. Desany, W. L. Jones, Q. Liu, B. Wang et al., 1996 Regulation of RAD53 by the ATM-like kinases MEC1 and TEL1 in yeast cell cycle checkpoint pathways. Science 271: 357-360.

Santocanale, C., and J. F. X. Diffley, 1998 A Mec1- and Rad53dependent checkpoint controls late-firing origins of DNA replication. Nature 395: 615-618.

SCHAR, P., 2001 Spontaneous DNA damage, genome instability, and cancer-when DNA replication escapes control. Cell 104: 329332.

Shiloh, Y., 1997 Ataxia-telangiectasia and Nijmegen breakage syndrome: related disorders but genes apart. Annu. Rev. Genet. 31: 635-662.

Shiloh, Y., 2001 ATM and ATR: networking cellular responses to DNA damage. Curr. Opin. Genet. Dev. 11: 71-77.

Sia, E. A., C. A. Butler, M. Dominska, P. Greenwell, T. D. Fox et al., 2000 Analysis of microsatellite mutations in the mitochondrial DNA of Saccharomyces cerevisiae. Proc. Natl. Acad. Sci. USA 97: 250-255.

Singer, M. S., and D. E. GotTschling, 1994 TLC1: template RNA component of Saccharomyces cerevisiae telomerase. Science 266: 404-409.

Teng, S.-C., and V. A. Zakian, 1999 Telomere-telomere recombination is an efficient bypass pathway for telomere maintenance in Saccharomyces cerevisiae. Mol. Cell. Biol. 19: 8083-8093.

Tercero, J. A., and J. F. X. Diffley, 2001 Regulation of DNA replication fork progression through damaged DNA by the Mec1/Rad53 checkpoint. Nature 412: 553-557.

Thomas, B. J., and R. Rothstein, 1989 Elevated recombination rates in transcriptionally active DNA. Cell 56: 619-630.

Usui, T., H. Ogawa and J. H. J. Petrini, 2001 A DNA damage response pathway controlled by Tel1 and the Mre11 complex. Mol. Cell 7: 1255-1266.

Weinert, T., 1998 DNA damage checkpoints: getting molecular. Curr. Opin. Genet. Dev. 8: 185-193.

Weinert, T. A., and L. H. Hartwell, 1990 Characterization of $R A D 9$ of Saccharomyces cerevisiae and evidence that its function acts post-translationally in cell cycle arrest after DNA damage. Mol. Cell. Biol. 10: 6554-6564.

Weinert, T. A., G. L. Kiser and L. H. Hartwell, 1994 Mitotic checkpoint genes in budding yeast and the dependence of mitosis on DNA replication and repair. Genes Dev. 8: 652-665.

Wierde, M., C. N. Greene, A. Datta, S. Jinks-Robertson and T. D. Petes, 1996 Destabilization of simple repetitive DNA sequences by transcription in yeast. Genetics 143: 713-721.

Zhao, X., E. G. D. Muller and R. Rothstein, 1998 A suppressor of two essential checkpoint genes identifies a protein that negatively effects dNTP pools. Mol. Cell 2: 329-340.

Communicating editor: L. Pillus 
